\title{
ELECTRICIDAD E INDUSTRIA EN LA ESPAÑA RURAL: EL IRATI, 1904-1961*
}

\author{
JOSEAN GARRUÉS IRURZUN URRUTIA
}

Universidad de Granada ${ }^{\mathrm{a}}$

\begin{abstract}
RESUMEN
El estudio del Irati pretende mostrar algunos de los comportamientos empresariales que se esconden detrás de las primeras fases del desarrollo eléctrico español y, a su vez, establecer nuevas preguntas sobre los factores y condicionamientos de los procesos regionales de industrialización. De hecho, esta firma representa una de las múltiples posibilidades abiertas por la electricidad en una región española no industrializada a principios del siglo Xx. La producción eléctrica generada en sus saltos explica la creación del mayor complejo industrial integrado en España alrededor de la primera transformación de la madera (serrerías y destilación química) y su comercialización (ferrocarril), al tiempo que la venta de sus excedentes energéticos en el mercado más importante de Navarra. El análisis de esta última actividad, además, permite ofrecer un modelo explicativo alternativo y complementario al clásico —realizado desde las mayores firmas—, sobre la

* Una primera y extensa versión de este trabajo fue financiada por la Fundación de Empresa Pública y publicada como Documento de Trabajo 9701 del Programa de Historia Económica, 1997. Agradezco las observaciones y comentarios que, en el curso del trabajo, me han ido ofreciendo Arizkun, Comin, Gómez Mendoza, Maluquer, Martín Rodríguez y Nadal, así como los realizados por los evaluadores anónimos, que sin duda han contribuido a mejorar sustancialmente las primeras versiones del mismo. Los errores, naturalmente, son sólo míos.

a Departamento Teoría e Historia Económica. Facultad de Ciencias Económicas y Empresariales. Campus Cartuja, s/n, 18071 Granada. jgarrues@ugr.es.
\end{abstract}


progresiva articulación de los mercados eléctricos tradicionales en los mercados integrados de las grandes compañías españolas.

Palabras clave: Historia empresarial, Industrialización, Empresas eléctricas, Mercados eléctricos, Integración vertical

\begin{abstract}
The study of the Irati hydroelectric company aims to show some of the business strategies behind the first stages of the development of electricity in Spain and, in turn, pose new questions regarding the factors and conditioning elements of the country's regional industrialization processes. In fact, this firm represents one of the many possibilities electricity brought to non-industrialized Spanish regions at the start of the 20th century. The electricity generated by its falls explains the creation of Spain's largest integrated industrial complex built up around the initial processing of timber (saw-mills and chemical distilling) and its commercialization (railways), along with the sale of its energy surpluses on the most important market in the region of Navarre. Furthermore, the analysis of this latter activity allows us to offer an explanatory model that is both an alternative and a complement to the classical model — that provided by the largest firmsconcerning the progressive incorporation of the traditional electrical markets into the integrated markets of the major Spanish companies.
\end{abstract}

Keywords: Business History, Industrialization, Electric Utilities, Electricity Markets, Vertical Integration

JEL Classification: N94, O14, L94, L22, L13

«Nature's action is complex; and nothing is gained in the long run by pretending that is simple, and trying to describe it in a series of elementary propositions», Marshall, A., Principles of Economics, vol. 1, second edition, London, Macmillan and Co., vol. 1, 1891, p. xiv.

El crecimiento económico moderno conoció con el nacimiento y desarrollo de la electricidad un avance incuestionable. Desde finales del siglo XIX la utilización de la energía eléctrica iba a cambiar los procesos productivos en la rama más dinámica del desarrollo económico, la industria, e iba a influir decisivamente en los modos de vida de la población en general, tanto en su trabajo como en su domicilio. La mayor o menor profusión de la electricidad, sin embargo, fue muy distinta en unas y en otras regiones, en función de múltiples factores, aparte de los tecnológicos, esencialmente ligados a la oferta (la dotación de recursos físicos — hidráu- 
licos o térmicos- y humanos — tradición empresarial—), a la demanda (estructura industrial y urbana, así como fuentes alternativas de suministro energético) y al mercado (la configuración espacial — dispersa o integrada- y económica de la red empresarial — desde el monopolio hasta la competencia-) que iban a tener una incidencia clara en el precio y la calidad del suministro. De acuerdo con ello, no es extraño que la Historia Económica, especialmente animada por el nuevo papel que representa la energía tras la primera crisis del petróleo, le haya prestado una atención creciente ${ }^{1}$.

La industria navarra tiene una larga tradición, aunque su capacidad de transformar el entorno económico y social ha ido incrementándose con el tiempo, especialmente ligada a su mejor articulación con otros espacios regionales. A finales del siglo XIX y principios del XX se modificaron los rígidos vínculos de integración económica e institucional previos, de un lado, la especialización y modernización agrícola fomentó el desarrollo agroindustrial y, de otro, las economías de escala y diversificación — vinculadas a la Segunda revolución tecnológica- proporcionaron nuevas áreas de negocio en el ámbito industrial y urbano (electricidad, cemento y química). Aun así, hubo que esperar hasta mediados de los años 50 para que la industrialización fuera consolidándose como la actual vía de especialización de la economía navarra ${ }^{2}$.

En el proceso de industrialización navarro de finales del siglo XIX y primer tercio del xx la electricidad representó — dadas sus buenas dotaciones hidráulicas y a pesar de su limitado nivel de interconexión eléctrica- una buena oportunidad para soslayar las tradicionales restricciones que había sufrido esta provincia a la hora de aprovechar la energía procedente de la máquina de vapor. Con todo, la debilidad del proceso de industrialización navarro, profundamente vinculado a las pequeñas industrias de bienes de consumo, iba inexorablemente a condicionar el ritmo de adopción de la electricidad y, por ende, su nivel de consumo. De hecho, la difusión de la electricidad dentro de las industrias alimenticias (harinas, compuestos, destilados y conservas ${ }^{3}$ ), sector líder hasta los años 60, tuvo un alcance desigual, y la electrificación del resto de ramas productivas, conocido el fuerte arcaísmo tecnológico de muchas de sus actividades, fue llevada a cabo por sus mayores empresas. La ausencia de importantes compañías de electricidad, por otro lado, explica que estas firmas asumieran un nivel de autoproducción relativamente elevado. A la altura de 1923, por ejemplo, la

${ }^{1}$ Un interesante repaso sobre los diferentes estudios realizados en torno al mundo de la electricidad en España se puede ver en Cayón (2001). Para disponer de una visión general del sector eléctrico español, aunque no necesariamente coincidente en sus planteamientos y conclusiones, Maluquer (1983, 1987 y 1992), Antolín (1988 y 1999b), Núñez (1994b y 1995), Sudrià (1987a y 1990), Sudrià \& Antolín (1994) y Tena (1988).

2 Arizkun (2001) y Garrués (2006).

${ }^{3}$ Garrués (1997b). 
importante compañía vizcaína Hidroeléctrica Ibérica no estaba dispuesta a introducirse en el mercado de Pamplona a no ser «que se reuniera un núcleo importante de consumidores» ${ }^{4}$.

En este marco, el estudio de El Irati, S.A., tiene interés desde varios puntos de vista. Por un lado, es una de las empresas navarras más importantes de la primera mitad del siglo Xx y representa uno de los ejemplos más interesantes de las múltiples posibilidades abiertas por la electricidad en el terreno industrial. No en vano, la producción eléctrica generada en sus saltos le permitió la creación del mayor complejo industrial español en torno a la primera transformación (serrerías eléctricas y destilación química) y comercialización (ferrocarril eléctrico) de la madera ${ }^{5}$, al tiempo que permitió la venta de sus excedentes eléctricos en el mercado más importante de la provincia, Pamplona. El estudio de esta última actividad resulta atractivo, por otro lado, porque permite ofrecer un modelo explicativo, complementario y original — desde la perspectiva de los perdedores - sobre la articulación de los sistemas eléctricos tradicionales (v. gr. el navarro) en los progresivamente más integrados de las grandes compañías españolas (en este caso Iberduero) ${ }^{6}$. Esta perspectiva de análisis debe ser tenida en cuenta si se comparte, como es el caso, la frecuente distorsión que según Hannah (1997, pp. 2-3) viene sufriendo la Historia de la Empresa en los últimos tiempos: «Our current knowledge of survivors dominates our impression of the typical experience and their triumphs are lionised; while the history of the failures is forgotten or considered untypical». Si esta afirmación resulta pertinente para muchos sectores productivos, alcanza un grado superior en el eléctrico. Es cierto que cada día se conocen más y mejor las principales líneas de evolución del sector eléctrico español, pero también lo es que queda mucho por investigar sobre lo que Garrues (1997b) viene denominando sistemas eléctricos tradicionales, aquellos que operaron en la mayoría de las regiones peninsulares desde finales del siglo XIX hasta la II Guerra Mundial. La prioridad conedida a la gran empresa, bajo los esquemas chanlerianos o sin ellos, derivada de la escasa recompensa académica que conlleva estudiar un conjunto extraordinariamente amplio de firmas, que no siempre han dejado un fácil rastro documental. De este modo, las aproximaciones con las que se cuenta, muy apreciables, en general se han realizado sobre todo en busca de un modelo nacional, prestando excepcionalmente atención a los casos particu-

${ }^{4}$ Libros de Actas del Consejo de Administración de Hidroeléctrica Ibérica (en adelante LACAHI), 30/7/1923, p. 254. Esta situación cambió en 1933 cuando esta compañía estudió colocar fuerza en la provincia de Navarra a través de una derivación de la línea del Cinca y previo acuerdo con Electra de Pamplona, LACAHI, p. 10/6/1933 y LACAHI, 25/8/1933.

5 Ello puede explicar, tal vez, que Navarra se situara entre las mayores provincias productoras de madera a mediados de los años cuarenta. Zapata (2001, p. 308).

${ }^{6}$ En este negocio, Irati consiguió mantenerse entre las veinte primeras autoproductoras eléctricas del Estado. 
lares, salvo cuando se trata de los pioneros y los desarrollos regionales más adelantados y precursores de los modelos integrados, como si estos últimos hubieran sido la norma, cayendo en un claro determinismo económico por el razonamiento ex post ${ }^{7}$.

En la medida que el caso del Irati encarna un ejemplo más de las ventajas e inconvenientes que algunas empresas familiares tuvieron dentro del proceso de industrialización español en la primera mitad del siglo XX, parece oportuno valorar su actuación también — tal y como sugieren los últimos estudios sobre este tipo de compañías-, no frente al modelo chandleriano, sino acomodándola al marco nacional y regional, en perspectiva comparada, dentro de sus particulares parámetros económicos e institucionales ${ }^{8}$. En este terreno se puede adelantar que los socios fundadores de la empresa, sin ser innovadores, sí que tuvieron la habilidad de conocer y utilizar la última tecnología eléctrica disponible para dar sentido industrial a una actividad tradicional ligada al mundo rural como la explotación maderera. Y esto pasaba, en una economía tradicional y relativamente poco articulada para el desarrollo industrial — como la navarra-, por adoptar una estrategia funcional novedosa para una empresa familiar del sector maderero español: la integración vertical ${ }^{9}$. En términos muy generales, como se ha desarrollado en otro trabajo ${ }^{10}$, las economías de escala y diversificación conseguidas por Irati dejaron de ser suficientes una vez que la mayor apertura comercial en los años 50 redujo su ventaja comparativa respecto a otras firmas de mayor tamaño y especialización. La sección eléctrica, de la que se da cuenta extensa en este artículo, resultó un buen negocio mientras el sector eléctrico español no estuvo

7 En cierta medida esta línea de interpretación también es dominante en otros países de nuestro entorno, si bien hay que reconocer que los trabajos de Annah (1979), para el Reino Unido; Caron et Cardot (1991) y Lévy-Leboyer et Morsel (1994), para Francia; y Balzani (1992) y Barone (1993a y b), para Italia, presentan un panorama sobre sus respectivos sistemas eléctricos tradicionales mucho más complejo y rico en matices.

8 A pesar de que Irati disponía de unas dimensiones relativamente importantes en la economía regional, no alcanzó el tamaño propio de las grandes empresas españolas y Domingo Elizondo ejerció como principal gestor —Presidente del Consejo de administración-y dispuso de las acciones suficientes como para disponer del control accionarial de la Compañía. Sobre la definición de empresa familiar en España y el cuestionamiento de la existencia de un modelo mediterráneo, véase Collí, Fernandez \& Rose (2003). Por otra parte, según la clasificación que nos ofrecen Carreras y Tafunell (1993) sobre la gran empresa en España, Irati tan sólo aparece en el puesto 108 en 1948.

${ }^{9}$ Sobre la teoría de la integración vertical, Casson (1984), acerca de las razones generales que la explican, Chandler (1977, pp. 287-289) y para el caso concreto del sector de la madera en Estados Unidos, Williams (1989).

${ }^{10}$ Así, la rentabilidad de las secciones maderera y química encontró sus mejores momentos cuando la competencia fue menor, especialmente durante la Gran Guerra y los primeros años del franquismo, mientras que la tímida liberalización del mercado español de los años 50 puso en evidencia su obsolescencia tecnológica. La sección del ferrocarril, ante la creciente competencia que representó el transporte de viajeros y mercancías por carretera, alargó su existencia por ser el principal canal de comercialización de los productos de la compañía. Garrués (1997c). 
suficientemente consolidado y sus mayores empresas no ejercieron su poder de mercado sobre las pequeñas y medianas eléctricas ubicadas en las regiones periféricas, la electrificación tuvo unos factores de carga bajos y se mantuvo una estrategia cooperativa con las empresas eléctricas locales frente a la eventual competencia interna y de terceros. Por otro lado, queda claro que la solución integradora de Irati vino influida por otro tipo de condicionantes económicos e institucionals, puesto que en otras regiones con abundantes recursos hidráulicos y madereros, como por ejemplo determinadas zonas de Canadá, Estados Unidos o los Países Nórdicos ${ }^{11}$, la temprana constitución de grandes compañías especializadas, de un lado, en producir y distribuir electricidad y, de otro, en proporcionar un transporte rápido a la madera (ferrocarriles y, más tarde, camiones) restringió este tipo de estrategia organizativa. La integración horizontal tampoco parece que en estas regiones tuviera demasiado éxito o, al menos, el suficiente, habida cuenta de que el sector de la madera es uno de los peor representados en los rankings de grandes empresas durante el siglo Xx, lo que hace pensar que el camino más frecuente de desarrollo estuvo más en la línea de la especialización flexible de las pequeñas y, sobre todo, medianas compañías, si descontamos la integración vertical hacia atrás o hacia delante, según el caso, de algunas firmas papeleras y forestales (clasificadas dentro del sector agrario) ${ }^{12}$.

Hay que aclarar, no obstante, que el presente trabajo no se aborda desde la ortodoxia chanleriana o su opuesta, the small is beautiful, sino desde el tradicional punto de vista de la Historia Industrial que recurre al estudio de un caso para ofrecer una mejor comprensión de los fenómenos de crecimiento regional y sectorial. De hecho, se pretende subrayar la importancia que para las economías periféricas han podido tener las pequeñas y medianas compañías eléctricas en las primeras fases de los procesos de industrialización regional ${ }^{13}$ —al igual que la debieron tener las distribuidoras en las regiones más industriosas ${ }^{14}$ - y desvelar alguna de sus estrategias de funcionamiento. En este último sentido, si la toma de decisiones de las firmas está informada por el pasado (is path-dependent), como seña-

11 United Nations (1996) ofrece una visión a largo plazo del proceso de explotación del monte y su conservación en los países madereros más importantes de Europa y Estados Unidos.

12 En las obras realizadas o dirigidas por Chandler (1977, 1980, 1990, 1997), las explicaciones o referencias a esta rama de actividad son más bien escasas. Llama poderosamente la atención, sin embargo, que en Estados Unidos el sector de la madera durante la segunda mitad del siglo XIX y los primeros años del siglo Xx fuera una de sus más importantes ramas industriales. Williams (1989, p. 6).

${ }_{13}$ Evidentemente, otros autores han utilizado la técnica del estudio de casos para abordar cuestiones similares en regiones no industrializadas —entre otros, Amigo (1991), Bernal (1993), Núñez (1993)—, pero en su mayoría con unos objetivos y una óptica diferentes.

${ }_{14}$ Tampoco se ha realizado una historia contextualizada, como por ejemplo Rose (1995) ha desarrollado para la electricidad y el gas en varias ciudades norteamericanas, siguiendo en parte las líneas de interpretación iniciadas por el seminal trabajo de Hugues (1983). 
la Jeremy (2002, p. 438), se compartirá con él que «failures are as important as successes» ${ }^{15}$, y la conveniencia de introducir una dosis de mayor complejidad, como se ha indicado, en el lineal desarrollo que hasta el momento se tiene sobre el sector eléctrico español, basado sobre todo en el comportamiento de sus mayores empresas y centrado en las regiones más industrializadas.

Evidentemente, este ambicioso objetivo no puede satisfacerse con el análisis de una única empresa, pero al menos el estudio del Irati pretende animar el debate de los especialistas en Historia Regional, Sectorial y de la Empresa en esta línea de trabajo. Dentro de las clásicas restricciones que imponen las fuentes y las preferencias del autor, el presente artículo se estructura en cuatro apartados. El primero explica la formación de la compañía. El segundo se ocupa de las decisiones de producción, el mercado y la tendencia seguida por los precios. De la evolución económico-financiera trata el tercero. Y el último, a modo de resumen, recapitula los aspectos más relevantes ofrecidos hasta entonces.

\section{PRIMEROS PASOS}

La constitución de El Irati, Compañía General de Maderas, Fuerzas Hidráulicas y Tranvía Eléctrico de Navarra en 1907 (de 1902 a 1907 Electra Aoiz $)^{16}$, tuvo como objeto social la producción de electricidad, mediante el aprovechamiento del salto situado en Ecay, para su comercialización en Pamplona y pueblos limítrofes, así como la construcción de un tranvía eléctrico (PamplonaSangüesa) para la explotación maderera del monte Irati (productos químicos y carbón vegetal). Su nacimiento, frente a lo que se ha mantenido ${ }^{17}$, no fue simplemente la consecuencia lógica del desarrollo de una eléctrica o la plasmación práctica de una idea original de Domingo Elizondo (Presidente del Irati), apoyada por la repatriación de capitales americanos. De hecho, esta compañía se establece en una etapa muy significativa para los negocios industriales navarros y en especial eléctricos: cuando la electricidad se había mostrado como la tecnología más idó-

15 Por lo que se refiere a la catalogación de los trabajos de la Historia Económica - y de la Historia de la Empresa en particular-, resulta muy esclarecedor el panorama historiográfico trazado por Pettigrew, Thomas \& Whittington, en el citado trabajo de Jeremy, sobre el nacimiento y desarrollo de la dirección estratégica.

${ }^{16}$ Las fuentes empresariales que se han utilizado en este trabajo, aparte de las citadas expresamente, han sido esencialmente los Libros de Actas de la Junta General de Accionistas y del Consejo de Administración, así como las Memorias anuales presentadas a la Junta General de Accionistas de las siguientes firmas: Hidroeléctrica Ibérica/Iberduero (1904-1944); Conducción de Aguas de Arteta (1893-1929/61); El Irati (1904-1961), y Electra Pamplona (1899-1946). Por otro lado, para conocer con mayor precisión el apoyo empírico de algunas de las argumentaciones que en este artículo se realizan véase Garrués (1997c).

17 Castiella (1989, pp. 114-138). 
nea para eludir los tradicionales estrangulamientos asociados a la explotación y comercialización de la madera (altos costes de extracción y transporte) en mercados distantes a precios competitivos.

Así, los promotores de Irati comprendieron que el aprovechamiento industrial de los importantes recursos existentes en los montes del Pirineo navarro, madera y agua, pasaba por la construcción de centrales eléctricas. Éstas, a la vez que regulaban el caudal del río Irati para el transporte de la madera, permitían obtener energía abundante y barata para electrificar las serrerías y el futuro ferrocarril. La rentabilidad del ferrocarril se iba a beneficiar, además, del tráfico de mercancías y viajeros de la Navarra Oriental y del servicio tranviario de su último tramo, Huarte-Pamplona. Como este tren tenía su conexión ferroviaria más próxima e importante en Pamplona, a 45 kilómetros, tuvo que adoptar un sistema de distribución de la energía eléctrica a alta tensión, muy poco extendido en España en aquellas fechas. Téngase presente que el ferrocarril eléctrico del Irati fue el segundo puesto en explotación en España, después del que circulaba entre Barcelona y Sarriá, que entró en funcionamiento en 1906 y de tan sólo 5 kilómetros.

La idea atribuida a Elizondo de establecer un tranvía eléctrico en Navarra tampoco fue muy original. De hecho, a finales del siglo XIX, a instancias de las casas de construcción de material eléctrico extranjero o de sus representantes en España, así como a través de la iniciativa local, se habían producido algunas tentativas en esta dirección, algunas de ellas teniendo en cuenta el desarrollo de los tranvías eléctricos del sur de Francia. Ahora bien, la superación de todos estos problemas necesitaba de la participación de personas con la suficiente cualificación técnica y empresarial, del apoyo financiero de otras dispuestas a arriesgar parte de sus capitales en una actividad con un alto grado de incertidumbre, e incluso del apoyo político y económico de las instituciones locales, provinciales (Diputación) y estatales. Por tanto, la magnitud de la empresa exigía cubrir diferentes etapas. Así, siendo Elizondo consciente de la importancia que para la consecución de sus fines tenía la electricidad y del interés que despertaba la industria eléctrica como foco de atracción de técnicos y capitales locales (los foráneos parece que dependían únicamente de la confianza deposita en él), parece lógico que aquél diera sus primeros pasos constituyendo una empresa de electricidad. El buen desarrollo de esta firma podía ser, asimismo, la mejor demostración pública de la viabilidad de sus proyectos.

En la constitución de Electra Aoiz, Elizondo contó con el apoyo y asesoramiento de un buen equipo de colaboradores, sin los cuales difícilmente hubiera podido desarrollar las bases de su idea. En el cuadro 1, donde se presentan sus socios fundadores y/o promotores, se puede comprobar cómo todos ellos, aunque de forma desigual, contaban con cierta experiencia empresarial. Destacaron por su vinculación con la industria eléctrica, Felipe Ortigosa, promotor en 1889 de la primera compañía navarra, así como el experimentado ingeniero Emilio Azarola, 
CUADRO 1

SOCIOS FUNDADORES DE ELECTRA AOIZ/EL IRATI Y SU PARTICIPACIÓN EN LA FUNDACIÓN DE OTRAS EMPRESAS INDUSTRIALES NAVARRAS (1886-1955)

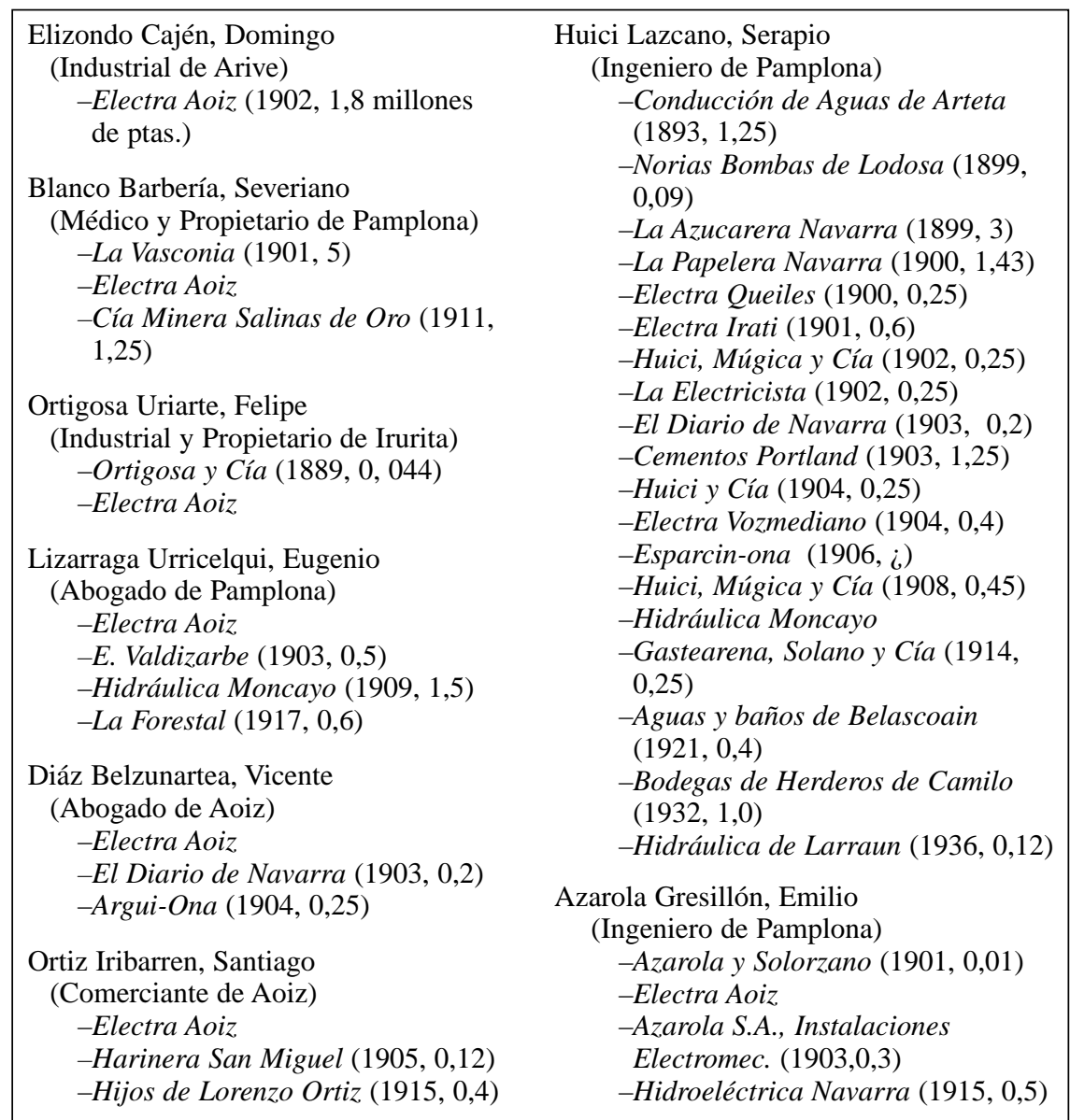

Fuentes: Libros de sociedades del Registro Mercantil de Navarra (1886-1955).

dedicado a la instalación y equipamiento de centrales, que fue sustituido en 1907 — momento de la fundación del Irati_ por el ingeniero Serapio Huici: el más distinguido empresario navarro de la primera mitad del siglo XX. No se puede olvidar, por otro lado, un hecho de especial relevancia en el desarrollo eléctrico español: que todos los proyectos de concesiones de aguas con fines industriales debían ser confeccionados o avalados por algún ingeniero. De este modo, algunos de 
ellos aprovecharon la ocasión para introducirse en los negocios eléctricos más significativos, primero, denunciando los saltos más rentables, después, participando en la formación de sociedades eléctricas y, en otros casos, formando sociedades de construcción y representación de material eléctrico. Así pues, este sector les prestó la ocasión de contactar con aquellos capitalistas más dinámicos y participar en la constitución de empresas de diverso tipo ${ }^{18}$. En este contexto se debe entender la vinculación de Elizondo con Huici, porque éste contaba con la preparación técnica, el capital necesario y, sobre todo, un perfecto conocimiento del mercado de electricidad navarro, lo que hacía de él un compañero ideal en la creación y desarrollo de una empresa de las características del Irati. No fue ajeno tampoco a la formación de la compañía - como ocurre en la mayoría de las más importantes firmas navarras - la presencia de profesionales liberales e industriales con relativa infuencia en la vida política provincial, de acuerdo con la formación de los primeros grupos empresariales que, a través de las tradicionales vinculaciones familiares endogámicas, iban a disponer de una creciente influencia en el principal órgano de representación de la provincia, la Diputación.

Por otra parte, pese al importante paquete accionarial de los mayores socios ${ }^{19}$, la compañía difícilmente se hubiera desarrollado sin contar con el apoyo de un grupo de medianos y pequeños accionistas. Es verdad, por tanto, que en la formación del Irati tuvo mucha importancia el capital repatriado de Sudamérica, pero también resulta claro que la participación del capital local tuvo tanta significación como el primero. Otra cosa distinta es que la concentración del mismo en torno a Elizondo, frente a la dispersión del resto, le concediera a este empresario una relevancia especial en la dirección de la sociedad. La contribución de los capitales regionales tiene que ver también con las precauciones tomadas por sus promotores a la hora de disponer del control de la firma. De hecho, antes de sacar a suscripción las primeras acciones, y ante el temor de que afluyeran demasiados capitales de foráneos, éstos hicieron una propaganda limitadísima del proyecto industrial, hasta el punto que «nadie conocía la importancia del negocio, excepción hecha de varios de (nuestros) (sus) amigos» ${ }^{20}$. Con posterioridad, las necesidades financieras del desarrollo empresarial extendieron la presencia de los capitales regionales, toda vez que resultó necesaria la colaboración de varias entidades financieras navarras ${ }^{21}$.

\footnotetext{
${ }^{18}$ Entre otros, Passer (1988), Bernal (1993) y Antolín (1999).

${ }^{19}$ Los cuatro mayores poseían el 36,8 por cien de las acciones, siendo el capital invertido de origen americano aproximadamente del 41,7 por cien. Libros de Actas de las Juntas Generales del Irati del 3 de mayo de 1911, del 2 de marzo de 1930 y 27 de julio de 1944 (en adelante CAEIr) y Memorias anuales de la Junta General de Accionistas del Irati (en adelante MEIr) (1909, p. 5).

${ }^{20}$ MEIr (1909, p. 6).

${ }^{21}$ Entre los mayores accionistas, en 1944, por ejemplo, se encontraban el Crédito Navarro (2.968), la Vasconia (1.904), el Banco de San Sebastián (1.080), sobre un total de 55.383 acciones;
} 
Los socios fundadores del Irati no sólo manifestaron sus dotes empresariales en la constitución de la compañía, sino que también fueron piezas claves de su primer desarrollo. Prueba de ello es, por ejemplo, la constante preocupación por implantar los métodos de producción más modernos en las nuevas secciones de la empresa (de manera especial en la sección del ferrocarril y en la de destilación).

El ferrocarril eléctrico Pamplona-Aoiz-Sangüesa (inaugurado el 23 de abril de 1911) fue el primero construido en España por su longitud, pero, sobre todo, por la innovación que suponía emplear un sistema de tracción por corrientes alternas simples, ideado por M. Latour. La instalación del aserradero de Aoiz fue, evidentemente, menos complicada. La electrificación de las serrerías no era un fenómeno tan novedoso, puesto que otras firmas ya lo habían realizado con anterioridad en localidades próximas. Por ello, la preocupación de los directivos de la compañía se concentró fundamentalmente en captar mercados donde poder colocar su producción. Con este fin, Lizarraga realizó varios viajes a las más importantes plazas consumidoras de madera del Estado y al parecer con bastante éxito, habida cuenta de que la empresa consiguió una rápida penetración de sus productos. La sección química no se quedó a la zaga en la incorporación de moderna tecnología. La destilería de Ecay (Aoiz), donde se obtenía carbón, acetato de cal, acetona, ácido acético, alcohol metílico, brea y otros derivados, fue también «sometida en la parte industrial a los progresos científicos para la producción, y en la comercial a las necesidades del mercado nacional y extranjero» ${ }^{22}$, previa visita de las principales casas extranjeras (Francia, Alemania y Austro-Hungría). En 1926, fruto de su excelente funcionamiento, la Revista La Energía Eléctrica llegó a decir que Irati había conseguido que el industrial español, en estos productos, no fuera tributario del extranjero.

\section{DECISIONES DE PRODUCCIÓN, MERCADO Y APROXIMACIÓN A LOS PRECIOS}

En términos generales, parece conveniente distinguir en el comportamiento de Irati, atendiendo a su diferente posición en el mercado eléctrico de Pamplona, tres grandes etapas: libre competencia (1904-15), autorregulación (1916-36/42) y progresiva integración en torno a Iberduero (1937/43-1958), si bien los desajustes productivos iniciados en la Guerra Civil, a efectos expositivos, justifican su inclusión en la última etapa, cuando aún estaba vigente el cártel eléctrico pamplonés.

siendo 28.518 las correspondientes a los 31 mayores (> 500 acciones). A la altura de 1949, por ejemplo, sólo el 9 por cien de los capitales de la empresa estaba en manos extranjeras (9.700 acciones). Comité de Gerencia del Irati, 3/4/1950, p. 146.

${ }^{22}$ MEIr (1909, p. 9). 


\subsection{La penetración de Aoiz/Irati y la reestructuración del mercado eléctrico de Pamplona (1904-15)}

Como se ha indicado, Electra Aoiz se constituyó en agosto de 1902 con la idea de dedicarse a la producción y distribución de energía eléctrica en Pamplona y los pueblos limítrofes a su línea. Ésta comenzó su explotación en 1904 a partir del aprovechamiento hidroeléctrico de Ecay (Aoiz). En aquellas fechas actuaban en Pamplona, aparte de la Electra municipal, tres compañías: La Electricista, Electra de Pamplona y Conducción de Aguas de Arteta. Las dos primeras (hidráulico-térmicas), a partir de la rivalidad planteada por Arteta (hidroeléctrica), se vieron obligadas a renovar sus fuentes de suministro a través de un contrato con Electra Irati (1901) ${ }^{23}$ y con Hidroeléctrica Franco-Española (1904), respectivamente (cuadro 2). Esta reestructuración del mercado tuvo en su haber la virtud de liberar a las dos primeras eléctricas citadas de su estrangulamiento productivo, pero en su debe, el hacerlas sumamente vulnerables y dependientes de sus únicos proveedores. Ello fue aprovechado por los promotores de Electra Aoiz para introducirse en el mercado de la capital navarra, mediante la absorción de La Electricista (1904), una vez fracasado su intento de hacerse con los activos de Pamplona.

Aunque Electra Aoiz comenzó su explotación con los elementos de producción y distribución de La Electricista ${ }^{24}$, sus nuevas disponibilidades hidroeléctricas (1906, Artozqui - $360 \mathrm{~kW}$ - y 1910, Aoiz - 1.152 kW-) y de distribución (1911, 2. ${ }^{a}$ línea Artozqui-Aoiz-Pamplona) le permitieron aumentar rápidamente su producción y, con ello, mejorar su posición competitiva respecto a las viejas firmas hidráulico-térmicas de Pamplona, al mismo tiempo que una singular y moderna integración vertical en el sector maderero español. En cuanto al primer particular, Aoiz rescindió el contrato que tenía con Electra Irati y se hizo rápidamente con un tercio del mercado de Pamplona que, dado el limitado desarrollo fabril de capital navarra, se caracterizaba por el dominio de los consumos domésticos —alumbrado- El Irati (sucesora de Aoiz), deseando ampliar su área de actuación, intentó comprar las instalaciones que la Franco-Española tenía en la capital. Elizondo (Presidente del Irati) señaló al respecto que con su adquisición «mejoraría notablemente la explotación de la industria eléctrica en Pamplona, al desaparecer las competencias y corregir los enormes abusos que comete(n)(ían) muchos abonados» ${ }^{25}$. Sin embargo, como esta operación la consumó Electra de Pamplona en 1908, cabe suponer que la rivalidad entre las firmas pamplonesas

\footnotetext{
${ }^{23}$ Esta firma fue la primera empresa española que transportó electricidad a $20 \mathrm{kV}$ a larga distancia $-32 \mathrm{~km}$ - , según el Boletín de la Cámara Oficial de Comercio y de la Industria de Navarra (1901, pp. 7-8)

${ }^{24}$ Esto es, la central de la calle Tejería en Pamplona $-250 \mathrm{cv}$ - , la fuerza arrendada a la Papelera de Villava $-110 \mathrm{cv}$ - y su red de distribución en la capital.

${ }^{25}$ CAEIr, 19-12-1907, p. 13.
} 
(Arteta, Pamplona e Irati) se acentuó. Aun así, la solvencia productiva de Irati, con casi la mitad de su producción destinada a los consumos propios ${ }^{26}$, debieron colocarle en una posición ventajosa. De hecho, Irati tardó más de un año en sumarse al acuerdo colusivo, firmado en mayo de 1914, entre Pamplona y Arteta, para «armonizar y unir las empresas de alumbrado de esta población de forma que se unifiquen en todo» ${ }^{27}$.

Las razones que animaron a la colusión, según las afirmaciones realizadas por los Consejeros, fueron esencialmente cuatro: $a$ ) las dificultades encontradas por las compañías para hacerse individualmente con el monopolio del mercado; b) las pérdidas generadas por la guerra de precios y el fraude de los abonados; c) imponer barreras de entrada a posibles competidores, y $d$ ) las buenas expectativas de crecimiento con la futura construcción del II Ensanche y la privatización del alumbrado público de la ciudad ${ }^{28}$. Aun así, parece ser que mientras que en Arteta y Pamplona pesaron más las motivaciones defensivas, en el caso del Irati lo fueron las organizativas. La primera firma encontró en el pacto un medio para amortiguar sus desventajas productivas, la segunda el escenario ideal para sanear su maltrecha situación económica, muy comprometida después de la compra de la Franco-Española, y la tercera la tranquilidad necesaria para aprovechar adecuadamente la excelente coyuntura económica de sus secciones forestal y química. Hay que tener en cuenta que estas prácticas cooperativas —que van desde el simple acuerdo hasta la fusión- fueron corrientes en la formación de sistemas eléctricos regionales ${ }^{29}$, aunque fueron más tempranos allí donde los consumos fueron más importantes, es decir, en los principales núcleos urbanos e industriales. A finales de 1908, por poner ejemplos cercanos, este proceso se estaba gestando en Bilbao en torno a Hidroeléctrica Ibérica; en 1911, en Zaragoza alrededor de ERZ; y un año después, en Vitoria ${ }^{30}$. Dos años después,

${ }^{26}$ Los consumos domésticos en Pamplona significaron algo menos de la mitad del consumo total. Inicialmente, la distribución de la potencia instalada fue la siguiente: Ferrocarril y talleres (500 cv); Destilación (70 cv); Aserradero (75 cv). Años después, Ancil (1911, pp. 316-321) señaló que Irati destinó $1.000 \mathrm{cv}$ al ferrocarril y de 1.200 a $1.400 \mathrm{cv}$ al resto.

${ }^{27}$ Libros de Actas del Consejo de Administración de Conducción de Aguas de Arteta, 18/1/1915, p. 152 y 5/7/1915, p. 167 y Libros de Actas del Consejo de Administración de Electra de Pamplona, 1/5/1919, p. 120.

${ }^{28}$ Las fuentes, desafortunadamente, no permiten realizar un ejercicio cuantitativo de ponderación acerca de cuál de las razones expuestas resultó más perniciosa para las tres compañías eléctricas de Pamplona, ni tampoco sobre cómo afectó la guerra de precios a sus cuentas de resultados porque, entre otras cuestiones, concurren otras realidades, como las economías de escala obtenidas con las nuevas instalaciones de generación en el caso de Irati o los costes financieros de la adquisición de la Franco-Española en el caso de Pamplona. Por su parte Arteta, libre de estos imponderables, sí que parece claro que sufrió una importante pérdida de rentabilidad entre 1907 y 1915.

${ }^{29}$ Sobre el concepto de sistema, véase Hughes (1983, pp. 5-7).

${ }^{30}$ Revista La Energía Eléctrica (1908a, pp. 116-117) y Revista La Energía Eléctrica (1908b, p. 80). De todos modos, para un conocimiento minucioso de las diferentes estrategias desple- 
MAPA 1

LA ELECTRIFICACIÓN EN ESPAÑA A PRINCIPIOS DEL SIGLO XX

Y LOS PRECIOS MÍNIMOS DE ALUMBRADO Y FUERZA MOTRIZ

EN LAS CAPITALES DE PROVINCIA

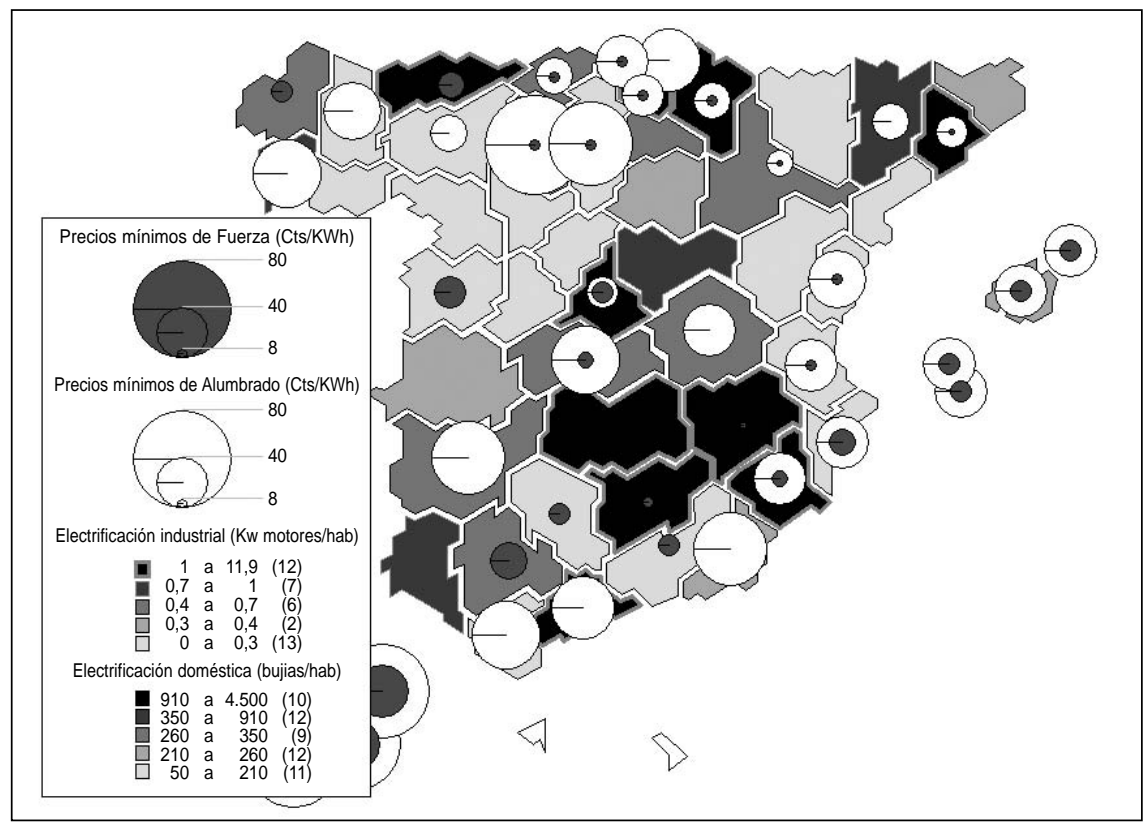

Fuentes: Gallego, E. (1915, p. 156) y Ministerio de Fomento (1910).

el Banco de Vizcaya impulsó la formación de una gran compañía con las electras afines (Hidroeléctrica Ibérica, Hidroeléctrica Española, Electra del Viesgo, Unión Eléctrica de Cartagena, Electra Valenciana, Unión Eléctrica Vizcaína y la Cooperativa Electra Madrid) para fortalecer sus posiciones financieras, de mercado e institucionales ${ }^{31}$.

gadas por Hidroeléctrica Ibérica, véase Antolín (1989). Para el mercado aragonés, Germán (1990, pp. 11-74). Libros de Actas del Consejo de Administración de Hidroeléctrica Ibérica, 10-41912, p. 164 y Revista La Energía Eléctrica (1912, p. 122). Otro ejemplo distinto de los clásicos de Barcelona y Madrid fue el producido en Valencia. Revista La Energía Eléctrica (1913, pp. 272). Para el caso catalán consúltese Maluquer (1983); y para el madrileño, Aubanell (1992) y Cayón (2002).

${ }_{31}$ Aunque la idea, asumida a finales de 1917 por Ibérica, fue finalmente rechazada por Española, que era favorable a estrategias menos unilaterales y drásticas. Española, ante los perjuicios de la futura competencia, ofreció un «proyecto de mutuo auxilio (...) para la defensa de los intereses del grupo filial». Libros de Actas del Consejo de Administración de Hidroeléctrica Ibérica, 25/11/1918, 
Los precios medios de venta ${ }^{32}$ del Irati en esta etapa no sufrieron grandes modificaciones, situándose entre 5,5 y $5 \mathrm{Cts} / \mathrm{kWh}$, aproximadamente. En un mercado competitivo como el de Pamplona, mantener unos precios bajos debió ser la mejor garantía para evitar la pérdida de clientes e incrementar la cuota de mercado. Y esto es lo que parece que hizo Electra Aoiz cuando comenzó su negocio, si bien esta política probablemente se vio lastrada en parte porque tuvo que respetar los contratos de su predecesora, La Electricista. De todos modos, no resulta fácil discernir hasta qué punto la competencia afectó económicamente a las tres eléctricas de Pamplona porque sus costes de producción se vieron influidos por varias circunstancias simultáneas, entre otras, positivamente, por las economías de escala de las nuevas instalaciones $y$, negativamente, por los costes financieros de las mismas.

Se supone que el mercado más interesante para Aoiz fue el industrial, dado que Arteta se había especializado en el consumo doméstico — alumbrado- con cierto éxito. De hecho, cuando contó con la energía del salto de Aoiz rebajó sus tarifas para este tipo de abonados, igualándolas con las de Arteta. Probablemente no las redujo más porque, a iguales precios, ofrecía una mayor garantía y calidad en el suministro. Así pues, en términos generales las tarifas establecidas por Irati el 28 de marzo de 1905, salvo en el caso citado de fuerza motriz, no sufrieron grandes modificaciones hasta septiembre de 1915.

pp. 74-75. Para conocer, de todos modos, en sus justos términos la creciente complejidad de estrategias inherentes al desarrollo eléctrico español y en concreto las desplegadas por Hidroeléctrica Española, véase Aubanell (2000).

${ }^{32}$ En relación con este tema, y con carácter previo al estudio de los precios medios, es preciso hacer una importante matización. Los precios a los que se hace mención son ingresos medios de venta, esto es, el cociente entre los ingresos de explotación y los kilovatios vendidos por la empresa. En realidad, para conocer con rigor la evolución de los precios habría que realizar un análisis individualizado de la evolución de las tarifas según los diferentes tipos y tramos de consumo, aparte de sobre las tarifas bilaterales negociadas entre la empresa y los grandes consumidores, bajo el supuesto difícil de cumplir de que las clasificaciones y escalas fueran constantes a lo largo del tiempo. Como esto resulta una labor poco menos que imposible y no está exenta de problemas, viene siendo habitual por los especialistas realizar comparaciones de los precios medios ingresados por las empresas para un conjunto de consumidores diferenciados. Esta última estrategia es la que se utiliza en este artículo. Se ha buscado, pues, teniendo en cuenta la mayor desagregación posible en función de la disponibilidad de fuentes, conocer la evolución de los precios (en este caso facturación media), atendiendo a los cambios en las tarifas y aclarando cuándo los cambios obedecían a alteraciones extraordinarias en el volumen del consumo, para aproximarnos grosso modo y en términos comparativos a las consecuencias que ello podía tener tanto para la empresa como para los consumidores. Esta estrategia de análisis se puede ver en muchos estudios históricos y recientes, por ejemplo, Iberduero (1968), Hannah (1982, pp. 293 y 295) y, de manera especial, Comisión del Sistema Eléctrico Nacional (1997, pp. 29-40). Sobre el sistema de tarifas aplicado en España y sus consecuencias sobre el proceso de concentración sectorial, Antolín (1988). 


\subsection{El oligopolio autorregulado (1916-36/42)}

La situación del mercado de Pamplona cambió sustancialmente una vez que las tres compañías alcanzaron un acuerdo sobre los precios que debían regir y el reparto de sus zonas de influencia en el mercado de Pamplona. Ello les permitió centrar sus estrategias en adecuar sus medios de producción al crecimiento de la demanda, mejorar el servicio y, en definitiva, rentabilizar debidamente sus inversiones.

Si la positiva evolución del consumo hizo que los directivos de Irati estudiaran ampliar la capacidad de producción (a corto plazo mediante una máquina de vapor - $500 \mathrm{cv}$ - y a medio plazo merced a un nuevo plan de construcciones hidráulicas —el pantano de Irabia y el salto de Oroz-Betelu-), el cambio de esta variable modificó los planes iniciales (gráfico 1). De hecho, la central de Oroz-Betelu $(600 \mathrm{~kW})$, interconectada con la central de Artozqui, se puso en funcionamiento en marzo de 1923, aunque parte del retraso cabe imputarlo también a las dificultades encontradas en la importación de la maquinaria hidráulica ${ }^{33}$. Las sucesivas recrecidas del pantano de Irabia, no obstante, fueron paulatinamente mejorando la cobertura energética de la empresa, pero sobre todo su distribución estacional,

GRÁFICO 1

EVOLUCIÓN DE LA PRODUCCIÓN,

POTENCIA INSTALADA Y FACTOR DE CARGA DEL IRATI, 1904-1961

(medias móviles de tres años)

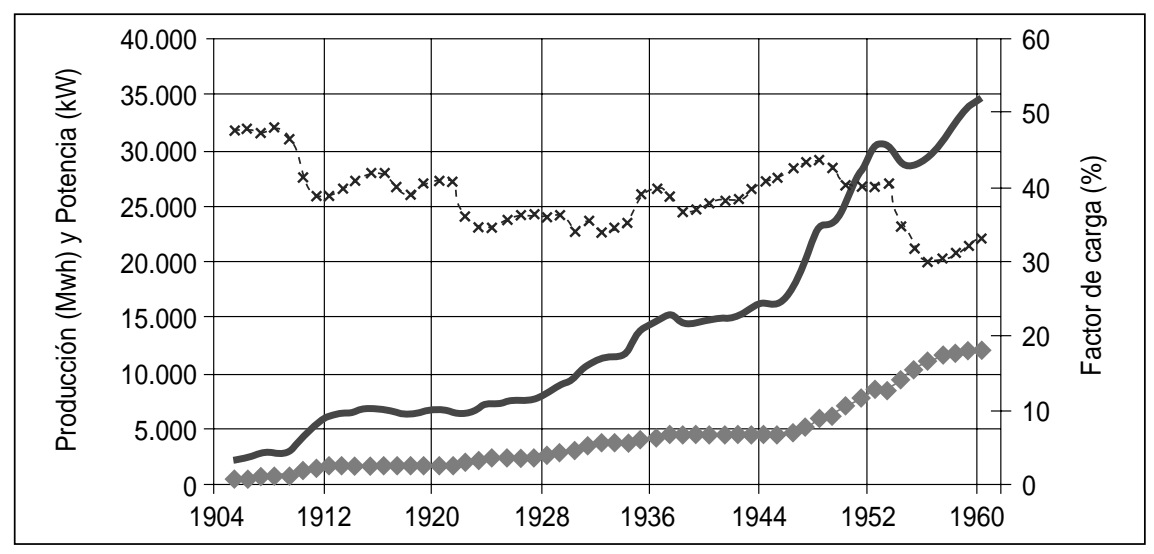

Fuentes: Cuadro A-1.

${ }^{33}$ El equipo eléctrico, dadas las circunstancias anormales por las que atravesaba Alemania, fue comprado a dos firmas madrileñas. 
especialmente comprometida durante las horas de máxima carga en los períodos de estiaje ${ }^{34}$.

El débil comportamiento del consumo, según el Consejo del Irati, parece justificarse por la concurrencia de varias circunstancias, de difícil ponderación a partir de los datos disponibles: $a$ ) la reducción de la jornada mercantil a ocho horas —1919_; b) la elevación de las tarifas a partir de la formación del cártel eléctrico de Pamplona (1915) y la eliminación de la establecida para consumos especiales $(1919)$; c) la debilidad del sector harinero tradicional de la Merindad de Sangüesa, como consecuencia de la competencia establecida por fábricas austrohúngaras pamplonesas, y $d$ ) la crisis que sufrieron algunos sectores industriales en España, una vez finalizada la I Guerra Mundial. El menor dinamismo relativo de la industria pamplonesa y de los consumos propios, por otro lado, hizo que cambiara la estructura del mercado del Irati. De tal manera que si en 1917 los diferentes tipos de consumo tuvieron una representación semejante (alumbrado de Pamplona - 35 por cien-, consumos propios - 35 por cien - y fuerza motriz de Pamplona -30 por cien-), una década después los usos domésticos pasaron a ser los dominantes (46 por cien) ${ }^{35}$.

La experiencia colusiva debió cumplir sus objetivos, porque años después, a raíz del nuevo desarrollo urbanístico de la capital navarra ${ }^{36}$, las Compañías Eléctricas de Pamplona (Irati, Arteta y Pamplona — en adelante CEP-) renovaron el pacto. En efecto, las eléctricas se repartieron el II Ensanche en tres zonas de actuación, en las que cada una tenía responsabilidades propias, pero manteniendo uniformidad de criterios en lo que se refería al establecimiento de tarifas, control del fraude, auxilio mutuo en casos de averías y la formación de un grupo

${ }^{34}$ Así pues, la construcción de la presa de Irabia fue la obra de mayor envergadura finalizada en esta década. Ésta, que se comenzó en 1921 con la intención de alcanzar en 1925 los 28 m y una capacidad de embalse de 6 millones de $\mathrm{m}^{3}$, se terminó tres años después de lo previsto, con un aforo de 9 millones.

35

DISTRIBUCIÓN DEL CONSUMO BRUTO DE ELECTRICIDAD DEL IRATI (1917-1927), SEGÚN SUS DISTINTOS USOS: FERROCARRIL, FUERZA MOTRIZ Y ALUMBRADO (GWH)

\begin{tabular}{|c|c|c|c|c|c|c|c|c|c|c|}
\hline Año & \multicolumn{4}{|c|}{ Pamplona } & \multicolumn{5}{c|}{ Usos propios } & Total \\
\hline & \multicolumn{2}{|c|}{ Alumbrado } & \multicolumn{2}{|c|}{ Industria } & \multicolumn{2}{|c|}{ Total } & Fuerza & Alumbrado & FFCC & \\
\hline & GWh & $\%$ & GWh & $\%$ & $\mathbf{G W h}$ & $\%$ & $\mathbf{G W h}$ & $\mathbf{G W h}$ & $\mathbf{G W h}$ & $\mathbf{G W h}$ \\
\hline 1917 & 1,84 & 35 & 1,57 & 30 & 1,84 & 35 & 0,90 & 0,19 & 0,76 & 5,26 \\
1927 & 2,92 & 46 & 1,66 & 26 & 1,71 & 27 & 1,72 & 0,14 & 0,85 & 6,29 \\
\hline
\end{tabular}

Fuentes: Elaboración a partir de Impuesto de Contribución Industrial y del Comercio (1917 y 1927).

${ }^{36} \mathrm{Si}$ en las dos primeras décadas del siglo xx el Área de Pamplona aumentó su población de hecho tan sólo en 5.000 habitantes aproximadamente, en las dos siguientes en 31.000. Garrués (2006), cuadro 6. 


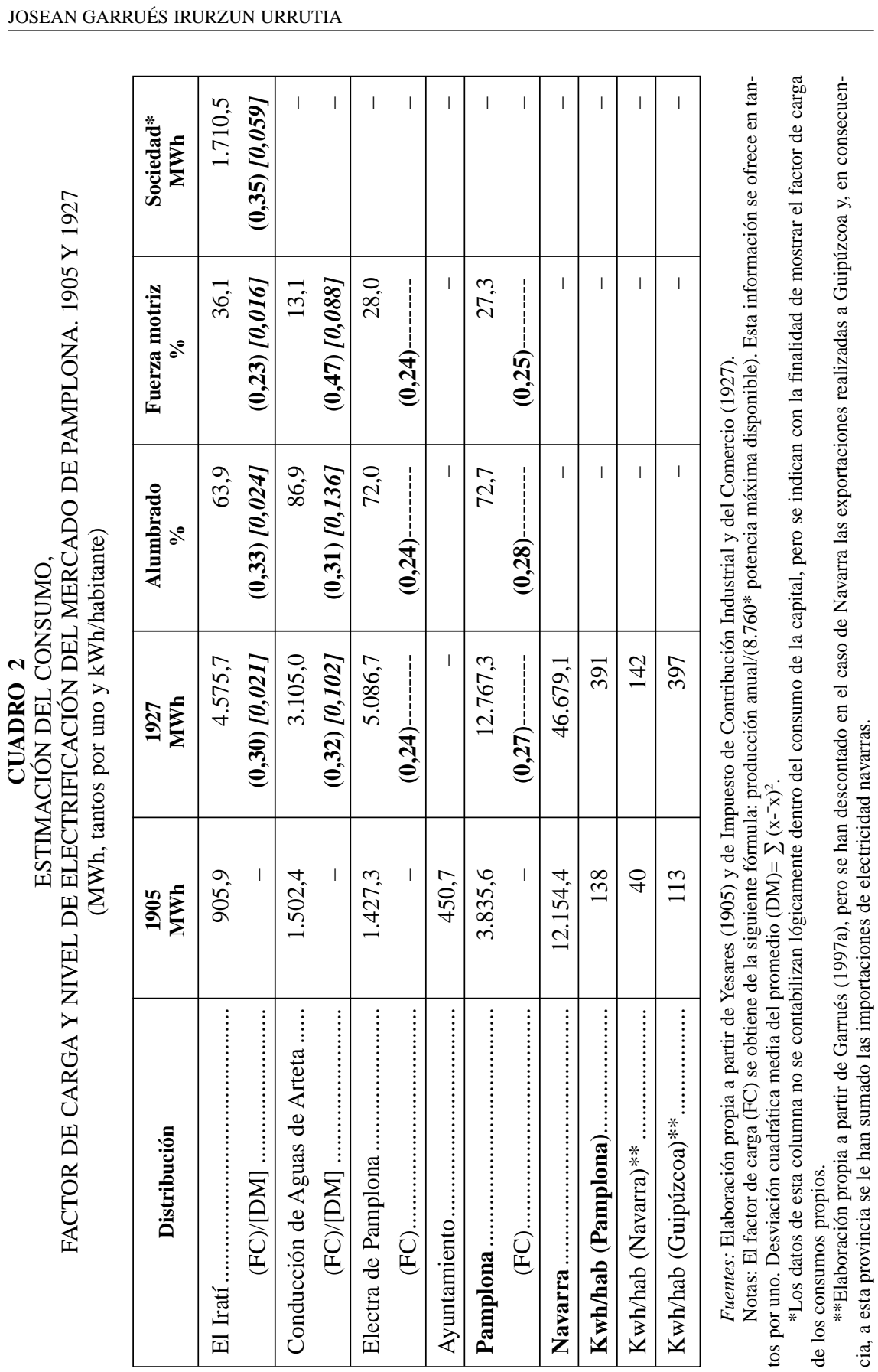


de presión frente a las autoridades competentes. Por lo que se refiere al Irati, esta firma remitió al Ayuntamiento, en noviembre de 1923, la memoria-proyecto de distribución de energía en su zona de actuación y, dos años después, participó, junto a las otras dos compañías de la ciudad, en el concurso público realizado por el Ayuntamiento para el alumbrado público del Ensanche. Las buenas relaciones entre las eléctricas se manifestaron en diferentes situaciones, pero de manera especial en los casos de auxilio mutuo. Así pues, los intercambios de energía se hicieron más frecuentes; sobre todo, por parte del Irati a las otras dos firmas, ya que éstas habían llegado al máximo aprovechamiento de su capacidad operativa en torno a los años treinta ${ }^{37}$.

Por el contrario, durante la primera mitad de los años treinta las disponibilidades productivas de Irati tuvieron un importante avance $\left(3.004 \mathrm{~kW}^{38}\right)$, en respuesta a la evolución del consumo de Pamplona y, sobre todo, a las demandas de nuevos e importantes clientes: La Papelera Española (400 kW —Guipúzcoa-) y la Confederación Hidrográfica del Ebro $(800 \mathrm{~kW})$. El progresivo desarrollo urbanístico de la ciudad, sin duda, explica el aumento del consumo doméstico, entre otras cuestiones porque desde 1926 las CEP se habían hecho cargo del alumbrado público municipal, así como del industrial, habida cuenta de que aumentó la fuerza demanda, primero, por las compañías constructoras y, más tarde, por los pequeños negocios allí establecidos.

Esta tendencia positiva del consumo se detuvo en el bienio 1933-34 porque, por un lado, los mercados de la madera y el ferrocarril del Irati fueron sensibles a la crisis económica española y, por otro, el consumo industrial se vio afectado, según el Consejo de esta sociedad, por varias circunstancias negativas: $a$ ) las averías producidas en la papelera de Rentería; $b$ ) el cierre de la fábrica de yeso de Echavacoiz, y c) la paralización de las obras de Yesa. La posterior aparente recuperación del consumo se debió a que el menor gasto de la Papelera y de la Confederación, como consecuencia de la Guerra Civil, fue más que compensado por el de la nueva caldera de destilación (1936) del Irati. Ésta, como corresponde

${ }^{37}$ Hay que tener en cuenta que este tipo de pequeñas y medianas eléctricas, dedicadas preferentemente al suministro del alumbrado, tenían una restricción estructural muy seria para realizar un aprovechamiento eficiente de sus recursos productivos, dada la fuerte variabilidad de la curva de carga diaria. La ausencia de información nos impide disponer del comportamiento de esta variable, pero los datos de la curva mensual y anual parecen confirmar este problema, en mayor o menor grado, para las tres compañías de la ciudad (cuadro 2).

38 Incorporación del salto de Usoz - 1931, $800 \mathrm{~kW}$-, ampliaciones de los salto de Oroz-Betelu -1929, $480 \mathrm{~kW}$ - y Artozqui - 1935, $760 \mathrm{~kW}$-, regulación del río Irati a través del pantano de Irabia — 1928, $1.000 \mathrm{~kW}$ - y mejoras en la red de distribución. Entre estas últimas se modificó la tensión Oroz-Pamplona, se creó la 2. a línea Artozqui-Aoiz y se reforzó la línea Aoiz-Pamplona. Del mismo modo, y como consecuencia del desarrollo urbanístico de la capital navarra, en 1930 las Compañías eléctricas de Pamplona cerraron la red de distribución que unía los barrios extramuros de La Milagrosa y San Juan e iniciaron reformas en la muy deteriorada red del casco antiguo. 
CUADRO 3

DISTRIBUCIÓN DEL CONSUMO

Y PRECIOS MEDIOS DE VENTA EN EL MERCADO DEL IRATI (1937)

\begin{tabular}{|c|c|c|c|c|c|c|}
\hline & MWh & $\%$ & $\mathrm{Cts} / \mathbf{k W h}$ & MWh & $\%$ & $\mathrm{Cts} / \mathrm{kWh}$ \\
\hline Consumo ........................... & 6.020 & 100,0 & 15,9 & 9.761 & 100,0 & 9,2 \\
\hline Mercado del Irati ............... & 4.216 & 70,0 & 17,2 & 3.314 & 34,0 & 20,7 \\
\hline Alumbrado ....................... & 946 & 15,7 & 41,0 & 1.193 & 12,2 & 34,0 \\
\hline Motores ............................ & 734 & 12,2 & 24,1 & 1.109 & 11,4 & 17,8 \\
\hline Calefacción .................... & 192 & 3,2 & 6,1 & 224 & 2,3 & 6,2 \\
\hline La Papelera Española.... & 2.345 & 39,0 & 6,3 & 788 & 8,1 & 8,5 \\
\hline Consumos propios .............. & 1.803 & 30,0 & 12,9 & 6.447 & 66,0 & 3,3 \\
\hline Alumbrado ...................... & 30 & 0,5 & $88,2 *$ & 43 & 0.4 & $57,8 *$ \\
\hline Motores ........................... & 211 & 3,5 & 9,6 & 184 & 1,9 & 8,9 \\
\hline Calefacción ....................... & 4 & 0,1 & 2,4 & 5 & 0,1 & 2,2 \\
\hline Tracción .......................... & 928 & 15,4 & 16,2 & 805 & 8,2 & 11,2 \\
\hline Caldera ............................. & 630 & 10,5 & - & 4.786 & 49,0 & 1,0 \\
\hline Destilería/Serrería .......... & - & - & 5,7 & 625 & 6,4 & 5,6 \\
\hline
\end{tabular}

Fuentes: Memorias de El Irati. 1938.

Notas: *Este precio está sesgado al alza porque se incluyen algunas instalaciones privadas próximas a la compañía y algunas concesiones gratuitas de energía.

a las actividades electroquímicas (y electrometalúrgicas), utilizó una cantidad ingente de energía: casi un tercio de la energía absorbida por Pamplona. Así pues, la incorporación de la Papelera y la caldera eléctrica cambiaron la distribución interna del consumo de las etapas previas. De tal manera que los consumos propios aumentaron su peso respecto a la energía comercializada en Pamplona, donde por primera vez los usos industriales se igualaron en importancia a los domésticos (cuadro 3).

En la medida en que las pérdidas de energía eran un mal casi crónico y el fraude de los abonados se fue intensificando, los gestores del Irati establecieron entre sus objetivos mejorar el sistema de interconexiones y de contabilización del consumo. Sin embargo, estas medidas comenzaron a tener verdadero sentido una vez que las eléctricas de la ciudad actuaron de manera mancomunada y decidida. De hecho, las campañas acometidas a principios de los años treinta por las CEP (v. gr. mediante «una inspección eficaz y constante» ${ }^{39}$ y mayores inversiones en la red), dio como resultado que la compañía a finales de esta década consiguiera unos niveles más acordes con los estándar del sector.

La presencia del cártel eléctrico tuvo una incidencia clara sobre los precios del mercado pamplonés. En efecto, con el nacimiento del oligopolio las eléctricas

39 JGEIr, 3/3/1932, pp. 73-74. 
CUADRO 4

PRECIOS MEDIOS Y DISTRIBUCIÓN

DEL MERCADO DE CONSUMO DE HIDROELÉCTRICA IBÉRICA (1935)

\begin{tabular}{|c|c|c|c|}
\hline Segmentos de consumo & MWh & $\%$ & Cts/kWh \\
\hline 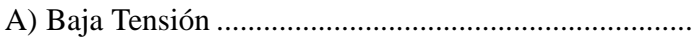 & 32.672 & 13,3 & 30,1 \\
\hline 1. Alumbrado y Usos domésticos ........................ & 16.371 & 6,7 & 42,5 \\
\hline 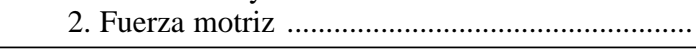 & 16.301 & 6,6 & 17,6 \\
\hline B) Alta Tensión & 212.570 & 86,7 & 7,5 \\
\hline 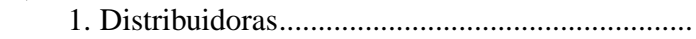 & 21.627 & 8,8 & 9,4 \\
\hline Distribuidora Eléctrica Guipuzcoana .... & 5.647 & - & 6,1 \\
\hline Eléctrica Irurat-Bat .............................. & - & - & 11,3 \\
\hline Cooperativa Eléctrica de Bilbao ............ & - & - & 11,3 \\
\hline ‥ $\quad$ n. & - & - & - \\
\hline 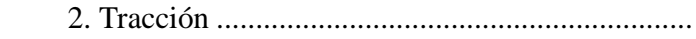 & 46.288 & 18,9 & 7,9 \\
\hline 3. Electroquímicas y Electrometalúrgicas ............. & 11.438 & 4,7 & 6,9 \\
\hline 4. Fuerza Motriz.................................................. & 133.218 & 54,3 & 7,1 \\
\hline 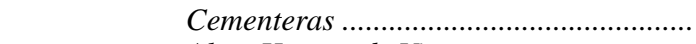 & - & - & 8,2 \\
\hline Altos Hornos de Vizcaya .......................... & - & - & 5,2 \\
\hline 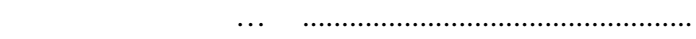 & - & - & - \\
\hline Total.. & 245.242 & 100,0 & 10,5 \\
\hline
\end{tabular}

Fuentes: Memoria Técnica el quinquenio 1935-1939 (1940).

decidieron mejorar sus coeficientes de explotación mediante el aumento de las tarifas (1915 y 1919), de tal manera que los precios medios entre 1916 y 1922 pasaron de 5 a $8,5 \mathrm{Cts} . / \mathrm{kWh}$. Estas subidas también se justificaban por ser el medio para corregir las deseconomías generadas por la inflación asociada a la Gran Guerra (cuando el precio real de la electricidad se redujo en un 46 por cien). Aun así, las tarifas de alumbrado por contador y, sobre todo, las de fuerza motriz fueron relativamente bajas con relación a otros mercados (mapa 1). Los precios medios de venta durante los años veinte (1923-29) se mantuvieron bastante estables, dado que la única variación producida en las tarifas fue una pequeña reducción del precio del alumbrado a partir de $1924^{40}$. Durante la primera mitad de los

${ }^{40}$ Por ello, las oscilaciones interanuales de aquéllos se debieron preferentemente a variaciones en el consumo industrial (tarifas graduales que premiaban los mayores consumos e incorporación o pérdida de algún cliente importante), así como a la diferente incidencia del fraude en los consumos domésticos. Con relación al primer aspecto se puede ofrecer, a modo de ejemplo, las siguientes variaciones de los ingresos medios: a) la desaparición a partir de 1926 de un cliente tan significativo como Cía. Navarra de Abonos Químicos, que disponía de tarifas bastante reducidas $(5,5 \mathrm{Cts} / \mathrm{kWh})$; b) el precio obtenido por el Ayuntamiento para el alumbrado público del Ensanche de Pamplona (18 Cts/kWh, desde mediados de 1926), y c) la renovación a la baja de algunos contratos importantes, como el de Sarasa, Usechi, Nagore y Cía. (200 cv invernales a 4,5 Cts/kWh para 12 horas y 5,5 para 6 horas, en 1924). 
años treinta (1930-34), sin embargo, aquéllos aumentaron ligeramente, y ello a pesar de la reducción de la tarifa del alumbrado público de Pamplona y la formalización de un contrato con Papelera a precios reducidos ${ }^{41}$, por lo que cabe imputarlo al aumento de las tarifas de fuerza invernal para calefacción y usos domésticos, desde marzo de 1930, y a la reducción del consumo industrial, en el bienio $1933-34^{42}$.

\subsection{Los desajustes productivos - restricciones-, el fin del oligopolio y el proceso de concentración en torno a Iberduero (1936/43-1958)}

La Guerra Civil y la inmediata postguerra supusieron un limitado crecimiento de la producción. El conflicto bélico, tal y como señaló el Consejo, impidió que el consumo «adquiera el ritmo normal de antes de la guerra» debido a «la disminución del trabajo en nuestras fábricas y las restricciones de energía en algunas industrias» ${ }^{43}$. De este modo, por ejemplo, no se pudo contar con el suministro para las obras del pantano de Yesa por su paralización, aunque esta inconveniencia fue compensada gracias al nuevo contrato firmado, a mediados de 1938, con La Papelera Española. A pesar del contexto depresivo que presidió la postguerra ${ }^{44}$, la recuperación de la demanda llevó al Consejo del Irati a reconocer la urgencia de ampliar sus instalaciones para sortear eventuales estiajes y atender los previsibles crecimientos del consumo. De hecho, en 1938 propuso el siguiente programa de obras: recrecimiento de la presa de Irabia (hasta los $36,8 \mathrm{~m}$ ), construcción del salto de Betolegui, de acuerdo con Papelera ${ }^{45}$, e instalación de un motor térmico de reserva en Pamplona $(800 \mathrm{~kW})$.

El retraso de las obras proyectadas (a las que se sumó, en 1943, el salto a pie de presa de Irabia), especialmente por las dificultades encontradas para disponer

${ }^{41}$ El precio definitivo (400 kW a $\left.6 \mathrm{Cts} / \mathrm{kWh}, 1930\right)$ fue considerado por los directivos del Irati como excesivamente bajo y, por tanto, poco remunerador. Esto no quiere decir que no se ofrecieran precios industriales menores (v. gr. el Ayuntamiento de Aoiz pagó $3 \mathrm{Cts} / \mathrm{kWh}$ el consumo de su moto-bomba).

${ }^{42}$ La sorprendente reducción de los precios (ingresos) medios en la segunda mitad de los treinta (1935-42) sólo se justifica por la entrada en funcionamiento de la caldera eléctrica de destilación del Irati; que consumía casi un tercio de la energía producida a un precio reducidísimo ( $1 \mathrm{Cts} / \mathrm{kWh}$ ). Este precio era inferior, por ejemplo, al que presenta Bartolomé (1995, p. 133), como coste máximo para la utilización de la electricidad en una treintena de actividades industriales a mediados de los años veinte. Ello, por otra parte, explica que se rompiera el paralelismo existente entre la evolución de los precios del Irati y Arteta de anteriores etapas.

43 JGEIr, 5/3/1938, pp. 133 y 139.

44 Entre otros, véase Catalán (1995) y Gómez Mendoza (2000).

45 Irati y Papelera llegaron a un acuerdo según el cual la primera firma cedía a la segunda la mitad del salto, comprometiéndose esta última a comprar la fuerza de la otra mitad durante los primeros cuatro años desde su puesta en explotación. 
de la maquinaria durante el conflicto europeo; el fuerte estiaje de 1942, que implicó una muy fuerte disminución de las reservas del pantano; y la absorción ese mismo año de Arteta llevaron a Irati, por primera vez en su historia, a tener que recurrir al auxilio de Hidroeléctrica Ibérica (a través de su filial Electra de Pamplona). El recrecimiento de la presa de Irabia un año después mejoró algo la situación, en tanto que permitió, según los directivos de la firma, atender la creciente demanda de energía sin que sufrieran sus abonados «las restricciones de fuerza que en el resto de España han motivado el paro parcial de las industrias» ${ }^{46}$. Alertados por el cariz que estaba tomando el asunto ${ }^{47}$, toda vez que no se recibía del extranjero la maquinaria de los nuevos saltos (Betolegui e Irabia) y persistían las sequías, los directivos del Irati incorporaron a su plan de obras la ampliación del salto de Aoiz (480 kW) y estudiaron la viabilidad de realizar nuevos aprovechamientos aguas arriba de su pantano.

La presión de la demanda debió hacerse cada vez más patente, toda vez que en el invierno de 1945 la empresa tuvo que establecer durante algunos días restricciones al consumo de «fuerza industrial desde las cinco de la tarde hasta la once de la noche, así como en el alumbrado de escaparates y parte del alumbrado público» ${ }^{48}$, además de verse obligada a prestarle ayuda a Electra Pamplona, su principal competidor. El agotamiento del pantano durante el otoño siguiente - fenómeno que en veintitantos años de existencia del embalse no había ocurrido-, le exigió conectar provisionalmente sus redes con las de Iberduero $(500 \mathrm{~kW})$.

Desde el punto de vista del mercado, el oligopolio fue perdiendo su sentido original una vez que Pamplona dio solución a sus problemas productivos, en 1934, mediante un contrato de suministro con la potente empresa vizcaína, Hidroeléctrica Ibérica, y que Arteta, por los mismos motivos, en abril de 1942, fue absorbida por Irati. De hecho, los directivos de esta última firma plantearon a Pamplona la necesidad de actualizar el reparto del mercado, porque no tenía en cuenta la producción de cada firma y, por otra, porque había llegado «el momento de obrar con libertad» en cada zona y fuera de ella ${ }^{49}$. Con la absorción citada, Irati buscó atemperar el riesgo de que su anterior aliada, Pamplona (apoyada por

46 JGEIr, 26/2/1945, p. 14.

47 El fenómeno de las restricciones, que afectó de manera desigual durante estos años a las diferentes regiones españolas, supuso, por ejemplo, que Irati recibiera peticiones de fuerza «incluso de industriales de fuera de Navarra» (Guipúzcoa). En el verano de 1943, el Gobernador Civil de Guipúzcoa mandó un oficio a Ibérica con la intención de que las «empresas productoras y distribuidoras que abastecen el mercado eléctrico de Guipúzcoa se presten mutuamente ayuda» y ordenó, en concreto, que lo hiciera con Fuerzas Eléctricas de Navarra $(25.000 \mathrm{~kW}$ diarios con una potencia de $2 \mathrm{kv}$ ) al precio convenido por ellas (21,5 Cts/kWh). LACAHI, 29/7/1943, p. 167. Sobre la incidencia de las restricciones en Guipúzcoa, Araquistain (1946, pp. 50-53) y en España, Sudrià (1987b, pp. 425-435).

${ }^{48}$ CAEIr, 24/11/1945, p. 50.

49 JGEIr, 25/2/1943, pp. 184-185. 
Ibérica/Iberduero) ${ }^{50}$, se convirtiera en la firma hegemónica de la capital navarra. El coste de la operación, sin embargo, resultó elevado toda vez que a los esperados gastos financieros de la compra tuvo que sumar los no previstos derivados de los retrasos productivos y las sequías, con un mercado todavía más amplio. Tal es así que, como se ha señalado, Irati tuvo que ser auxiliada por Ibérica (a través de Pamplona), su principal competidor.

Esta nueva realidad explica que en febrero de 1946 Irati, buscando eludir el desgaste económico que a medio plazo podía suponer la libre competencia en el mercado pamplonés, iniciara negociaciones con Pamplona con la intención de llegar a un nuevo convenio de reparto del abono manteniendo el equilibrio previo (2/3 a favor de Irati-Arteta). La absorción de Pamplona por Iberduero ese mismo año, sin embargo, dio un giro radical a la situación. No era lo mismo negociar con una compañía de ámbito local, que hacerlo con otra que - amparándose en sus ingentes disponibilidades productivas y sólido apoyo financiero- tenía en sus miras controlar buena parte del mercado centro-norte peninsular.

Así pues, los consejeros del Irati se entrevistaron con el director de Iberduero en abril de 1947 para establecer las bases de un nuevo convenio como si nada hubiera cambiado ${ }^{51}$. Aunque inicialmente coincidieron en los aspectos generales, Irati presentó algunas modificaciones porque pretendía suavizar el obligado trasiego que se iba a producir para encajar a cada sociedad en su cupo respectivo y porque era necesario puntualizar hasta dónde y cómo se iba a prestar la ayuda mutua. Este último asunto quedó pronto aclarado cuando Iberduero señaló que se refería exclusivamente a los casos de avería y no a los de restricciones. Más dificultades de arreglo encontró el primer tema, en la medida en que Irati consideró que el nuevo equilibrio de consumos y recaudaciones se debía lograr progresivamente, aplicando a Iberduero las nuevas peticiones de suministro, pero sin producir rápidos traspasos de antiguos clientes, como deseaba esta última. La voluntad de los directivos del Irati, a pesar del enrocamiento de las posturas que tuvo lugar en la reunión celebrada en enero de 1948, fue seguir negociando porque se encontraba presionada por su estrangulamiento productivo ${ }^{52}$, así como por la menor

${ }^{50}$ LACAHI, 21/6/1941, p. 123. Electra Pamplona prorrogó su contrato de suministro con Ibérica por 10 años, contando a partir de 1 de julio de 1944, concediendo a ésta la participación de un representante en su Consejo de Administración (Agustín Peña).

${ }^{51}$ El Convenio, según el Irati, debía garantizar «a ambas Sociedades la explotación del mercado de Pamplona, con igualdad de tarifas, reparto proporcional del nuevo abono y una máxima ayuda en casos de avería, facturándose entre ellos los suministros a precios normales». CGEIr, 10/4/1947, pp. 64-65.

52 Tal y como se ha indicado en otro apartado, tuvo que comprar energía a Iberduero con el fin de suavizar las restricciones al consumo y asemejar su servicio eléctrico con el de esta compañía en los otoños de 1946, 1947 y 1948. La conexión realizada en el primer año citado, mediante un transformador de $30 \mathrm{kv} / 2,5 \mathrm{kv}$ para obtener $500 \mathrm{~kW}$, fue la primera que Irati realizó en su historia con una empresa de ámbito supra-regional. 
ELECTRICIDAD E INDUSTRIA EN LA ESPAÑA RURAL: EI IRATI, 1940-1961

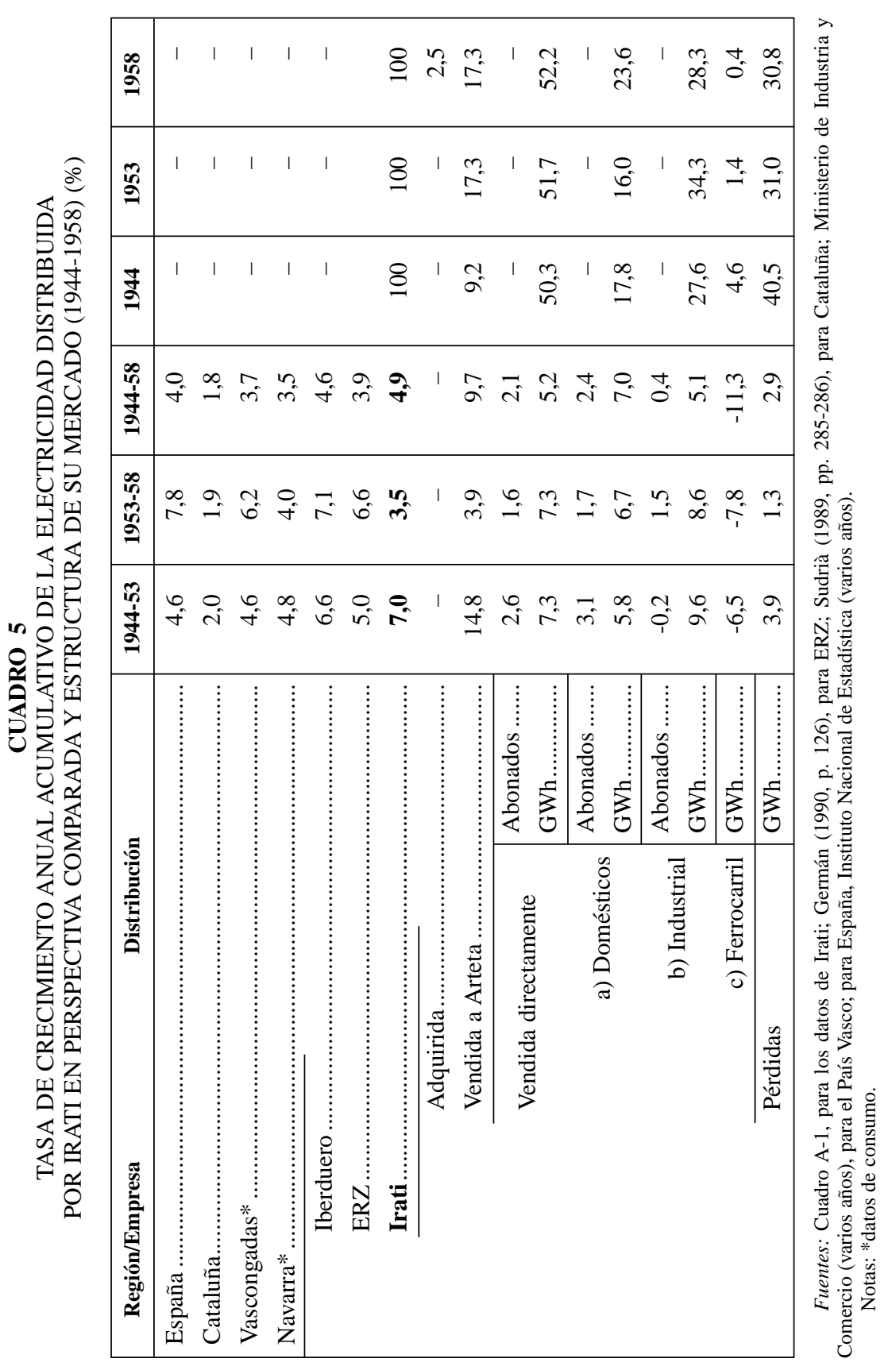


atención que la Administración prestaba a las pequeñas y medianas compañías a la hora de repercutir sobre los consumidores los precios de las suplencias y, sobre todo, su esfuerzo inversor para aumentar la capacidad de producción (vía tarifas).

A pesar de que en apenas seis años consiguió duplicar la producción de 1946, la compañía no logró atender de manera desahogada el crecimiento de su mercado. El acuerdo firmado entre ésta e Iberduero, en junio de 1947, sobre las suplencias de máxima ayuda y la puesta en explotación de la central a pie de presa de Irabia $(1.160 \mathrm{~kW})$ contribuyeron a suavizar las restricciones al consumo, pero aquél tuvo que ampliarse eventualmente (entre 8,6 y 12,5 MW) en agosto de 1950. El alivio que supuso la rápida ampliación de Aoiz $(1951 ; 1.512$ kW) y la posibilidad de utilizar completamente la central de Betolegui resultó ser meramente coyuntural, porque una vez más la prolongada sequía de 1952 le llevó a imponer restricciones al consumo y solicitar el apoyo de Iberduero (ahora a través de su filial en Navarra, Fensa). En términos comparativos, sin embargo, el hecho de que el crecimiento del mercado de consumo de Irati entre 1943 y 1953 creciera a una tasa anual acumulativa del 7 por cien, muy por encima de la media española $(4,6$ por cien) y de otras compañías próximas (Iberduero — 6,6 por cien — y ERZ — 5,0 por cien-), parece sugerir que las restricciones, siempre importantes para una compañía eléctrica, no alcanzaron los perjuicios económicos alcanzados en otros importantes mercados como en Cataluña (2 por cien $)^{53}$.

Aunque Irati consiguió solucionar las restricciones definitivamente mediante un contrato con Iberduero a principios de 1953 (1,5 MW constantes), su débil posición en el mercado de Pamplona le llevó a presentar a la firma vizcaína una nueva propuesta de convenio con los siguientes puntos: a) la indispensabilidad y urgencia de la instalación de una central térmica $(2.400 \mathrm{~kW}) ; b)$ la necesidad de que Iberduero presentara un proyecto que diera solución definitiva, teniendo en cuenta «los numerosos casos resueltos por ella», y $c$ ) el deseo de continuar las negociaciones iniciadas el mes de febrero ${ }^{54}$. Ante la ausencia de una contraoferta clara, los representantes del Irati en agosto de 1953 elaboraron un proyecto de bases para un posible convenio con tres propuestas: $a$ ) la compra de la Sección de Electricidad por Iberduero; $b$ ) la fusión del Irati por Fensa (filial de Iberduero), y c) la eliminación de los motores térmicos que Irati había acordado adquirir, siempre que Iberduero durante las negociaciones (máximo de seis meses) se comprometiera a facilitarle la fuerza necesaria en los estiajes y horas puntas del invierno ${ }^{55}$, que tampoco fue aceptada por Iberduero. A la empresa vizcaína no le inte-

53 Sudrià (1987b).

${ }^{54}$ CAEIr, 12/3/1953, p. 227 y CAEIr, 1/8/1953, pp. 235-236.

55 Irati descartó una cuarta posibilidad: la de convertirse, tras vender su distribución en Pamplona, en una firma netamente productora, que incrementara su producción a través de la red francesa (EDF). Bases para un convenio... (1953, pp. 1-8). 
resaban los saltos de la firma navarra, salvo si los compraba muy baratos, por ello estableció una serie formal de inconvenientes ${ }^{56}$ que, con el paso del tiempo, pusieron al Irati contra las cuerdas. En efecto, esta sociedad aceleró los trámites para la adquisición del equipo térmico, mientras le facilitó a Iberduero cuantos datos técnicos y económicos fueron necesarios para estudiar un futuro convenio. Además, la obligada conexión con la Red Nacional, exigida por la Dirección General de Industria, condenaba a ambas empresas a ponerse de acuerdo. Esta conexión se realizó provisionalmente en los primeros días de agosto de 1955 a través del transformador que Iberduero poseía en la subestación de Cordovilla (próxima a Pamplona). Con ella se rompía el tradicional aislamiento del sistema eléctrico del Irati, al integrar definitivamente sus líneas dentro de la más importante compañía española.

Finalmente, en 1958, Fensa y Cía. Eléctrica del Urumea (filiales de Iberduero) ya eran los mayores accionistas del Irati, aunque desde el punto de vista jurídico y fiscal ésta se mantuvo como firma independiente hasta el 30 de diciembre de 1986, momento en que se fusionó con Fensa ${ }^{57}$. A partir de entonces, Iberduero, interesado en la integración del mercado navarro en su sistema eléctrico, primero, mejoró, en primer lugar, las conexiones con Irati, después (1962), promovió un convenio entre Irati y Fensa, según el cual la compañía de Aoiz le vendía a la segunda toda su producción, y, más tarde (1976), otro convenio por el cual le arrendaba todas sus instalaciones. Lo que sucedió después fue la integración y modernización del sistema eléctrico del Irati dentro del integrado de Iberduero ${ }^{58}$.

Mientras todo esto sucedía, la sorprendente reducción del ritmo de crecimiento del consumo industrial entre 1953 y 1958 con relación al período 1943-53 ${ }^{59}$, precisamente en el momento en el que se estaba produciendo el despegue industrial de la capital navarra, muestra las limitaciones productivas sufridas por el Irati

${ }^{56}$ Básicamente fueron los siguientes: a) la dificultad para intercambiar el patrimonio del Irati por acciones de Iberduero; $b$ ) la inoportunidad, por cuestiones de régimen interno, de fusionar Irati con Fensa, y $c$ ) las dudas sobre cómo cubrir el coste de la solución térmica adoptada en última instancia por Irati.

57 Fensa adquirió el activo y el pasivo del Irati por 1.500 millones. El intercambio de acciones fue de dos de la segunda firma por tres de la primera. Parece claro que el mantenimiento del Irati como empresa independiente, desde el punto de vista jurídico, respondía a una política diseñada por Iberduero, bien por conveniencias organizativas de régimen interno, bien porque compensaba el trato fiscal recibido por la Diputación de Navarra, o por ambas a la vez.

58 Así, en octubre de 1959 entró en funcionamiento la línea Pamplona-Cordovilla (de 5 km y $66 \mathrm{kv}$ ), que ligaba a esta empresa con la Red Nacional, y en 1961, a través de la nueva subestación de Aoiz (20/66 kv) y la nueva línea Aoiz-Pamplona (66 kv), quedaban acopladas sus centrales con la red de alta tensión de Fensa. Como consecuencia de todo ello, en apenas ocho años, consiguió aumentar su factor de carga en un 30 por cien.

$59 \mathrm{Si}$ en 1953 mediaban entre ellos 10 puntos porcentuales, cinco años después tan sólo 4,7, aunque una pequeña parte se pueda justificar por la menor importancia de los usos propios (caldera eléctrica y destilería). 
y, por el contrario, las ventajas de Fensa — filial de Iberduero desde 1944 — para hacerse con los más importantes suministros de este mercado. Evidentemente, la competencia de Fensa no venía determinada por los precios, una vez fijadas las Tarifas Tope Unificadas, sino por la garantía y calidad del suministro prestado, sobre todo por lo que se refiere a los grandes clientes. En este contexto es fácil entender la insistencia y urgencia de Irati por contar con la nueva central térmica $(1955 ; 2.400 \mathrm{~kW})$, así como sus intentos por aprovechar cuantos recursos estuvieron en su mano para aumentar la producción, como por ejemplo, la reutilización de los grupos monofásicos utilizados previamente para mover el ferrocarril $(1958 ; 800 \mathrm{~kW})$ o su afán para atenuar las pérdidas y el fraude ${ }^{60}$.

Por lo que se refiere a la tendencia de los precios medios del Irati, en los años cuarenta (1942-52), tuvieron un aumento significativo, puesto que el kilovatio pasó de 10 a 16,5 Cts/kWh. Este crecimiento, sin embargo, no respondió a una subida general de las tarifas. En una primera fase (1941-46), más bien reflejó la reforma de 1942 sobre el modo de tarifar la fuerza motriz y el aumento del contrato de Papelera en $1945^{61}$ y, en la segunda (1947-52), respondió a las compensaciones establecidas por la Administración para los consumos de energía supletoria (en este caso de Iberduero ${ }^{62}$ ) y a la subida del precio del alumbrado público a finales de $1947^{63}$.

La sociedad, fuertemente afectada por la inflación (el precio real de la electricidad cayó un 77 por cien entre 1934 y 1952 — cuadro 6-), se sumó a la campaña de reivindicación sectorial llevada ante la Administración tendente a corregir el llamado déficit tarifario. Este requerimiento pareció satisfacerse en 1951, cuando el Gobierno aprobó las Tarifas Tope Unificadas para todo el Estado. Si el nuevo sistema tarifario fue aplaudido por todas las empresas del sector eléctrico, más aún, según los regentes del Irati, por aquellas pequeñas y medianas compañías que como la suya, además de tener «tarifas muy bajas en relación con las del resto de la Nación», no habían escatimado recursos económicos para aumentar su producción ${ }^{64}$.

${ }^{60}$ Entre ellas destacan: la instalación de la línea de Ayanz y, sobre todo, la sustitución de los antiguos postes de madera por postes metálicos entre Irabia-Aoiz (32 km).

${ }^{61}$ El contrato con Papelera de $250 \mathrm{~kW}$ constantes se transformó en otro, hasta que la central de Betolegui se pusiera en funcionamiento, al precio unitario de 9 Cts. Aunque posteriormente Irati buscó duplicar los precios establecidos en el contrato con Papelera (de 3 y $6 \mathrm{Cts} / \mathrm{kWh}$ a 6 y $12 \mathrm{Cts} / \mathrm{kWh}$ para la energía eventual y constante, respectivamente), una vez entrara en funcionamiento la central de Betolegui, tuvo que conformarse con una subida menor $(13 \mathrm{Cts} / \mathrm{kWh}$ menos el 15 por cien de transformación y transporte), dados los precios que regían en el mercado vasconavarro (Ibérica y filiales).

${ }^{62}$ Otro factor que explica este crecimiento fue la incorporación de Arteta como cliente y empresa filial del Irati, dado el peso que en esa compañía tuvieron los consumos domésticos.

${ }^{63}$ Este pasó de $16 \mathrm{Cts}$ a $24 \mathrm{Cts} / \mathrm{kWh}$.

${ }_{64}$ JGEIr, 6/3/1951, pp. 61-62. 
GRÁFICO 2

EVOLUCIÓN COMPARADA DE LOS PRECIOS

MEDIOS DE VENTA DEL IRATI, ARTETA E IBÉRICA (1904-1939)

$(\mathrm{Cts} / \mathrm{kWh})$ (medias móviles de tres años)

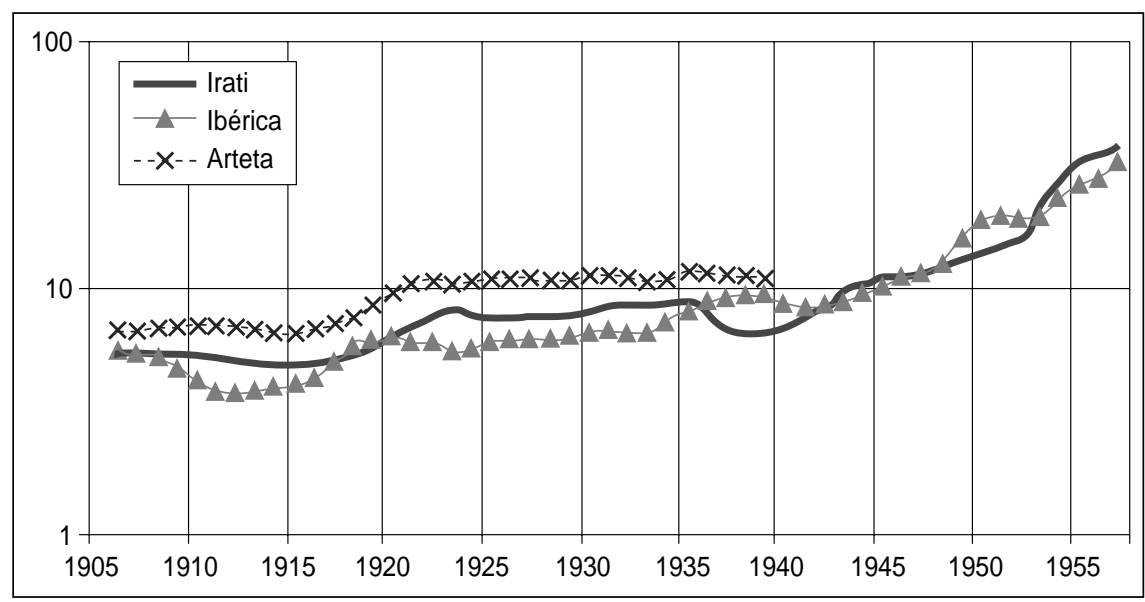

Fuentes: Cuadro A-1.

Las tarifas eléctricas recibieron nuevos impulsos en abril de 1955 y a mediados de 1956. Éstos, según los directivos del Irati, permitieron mejorar los dividendos repartidos y atenuar la subida salarial de 1956. Además, como más de la mitad de sus instalaciones eléctricas se construyeron con posterioridad a 1936, esta firma mejoró de forma importante sus ingresos (en torno a un 10 por cien) mediante las compensaciones de la OFILE. Como cabía esperar, los precios medios del Irati se multiplicaron entre 1952 y 1957 por 2,6, pasando de 16,5 a $42,7 \mathrm{Cts} / \mathrm{kWh}$, pero lo que es más importante, por primera vez después de veinte años los precios reales tuvieron una evolución positiva.

De la comparación de los precios medios de venta del Irati e Ibérica se puede apuntar que, si bien el cártel eléctrico de Pamplona no estimuló todo lo deseable el proceso de electrificación de la capital, a partir de la Guerra Civil este aspecto parece ser poco relevante. De hecho (salvando la diferencia que algunas grandes industrias tuvieron en la negociación de precios reducidos, así como los lógicos bajos precios de los consumos propios), ni los precios de alumbrado y fuerza motriz del Irati para pequeños clientes (que viene a corresponderse con el alumbrado y fuerza a baja tensión de Ibérica), ni los precios de fuerza motriz para los clientes importantes compararon de manera muy desfavorable con los de Ibérica (cuadro 5 y gráfico 4). Más bien se podría decir lo contrario, que los bajos precios relativos del Irati debieron intensificar los usos eléctricos frente a otras alternati- 
CUADRO 6

PRECIOS MEDIOS DE VENTA REALES

DEL IRATI E HIDROELÉCTRICA IBÉRICA/IBERDUERO (1904-1957) (ptas. de 1913)*

\begin{tabular}{|c|c|c|c|c|}
\hline \multirow{2}{*}{ Período } & \multicolumn{2}{|c|}{ Precios (Cts/kWh) } & \multicolumn{2}{|c|}{ Tasa de crecimiento anual (\%) } \\
\hline & Irati & Ibérica & Irati & Ibérica \\
\hline 1904-1915 …........................... & 5,2 & 4,5 & 3,0 & 5,6 \\
\hline 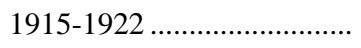 & 3,8 & 3,4 & $-1,8$ & 2,0 \\
\hline $1922-1941$............................... & 4,5 & 4,1 & 3,4 & 1,5 \\
\hline $1922-1929 \ldots \ldots$ & 4,8 & 3,7 & 1,2 & $-2,7$ \\
\hline $1929-1934 \ldots \ldots$. & 5,3 & 4,4 & $-2,8$ & $-5,0$ \\
\hline 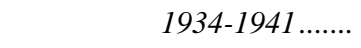 & 3,7 & 4,5 & 9,8 & 10,9 \\
\hline 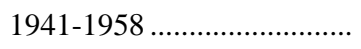 & 2,1 & 2,0 & 0,0 & 0,1 \\
\hline $1941-1952 \ldots \ldots$ & 2,0 & 2,2 & 6,3 & 3,7 \\
\hline $1952-1958 \ldots \ldots$. & 2,0 & 1,8 & $-9,9$ & $-6,0$ \\
\hline
\end{tabular}

Fuentes: Cuadro A-1.

Notas: * Precios deflactados según el índice elaborado por Maluquer (1989, pp. 521-522).

vas energéticas, sobre todo cuando los problemas de abastecimiento de carbón y gas-oil fueron evidentes. Este hecho, sin embargo, no pudo ser totalmente aprovechado por la eléctrica porque, al coincidir con una oferta constreñida y una rentabilidad debilitada, resultaba cada vez más complicada la captación de capitales para acometer nuevas inversiones productivas.

\section{EVOLUCIÓN ECONÓMICO-FINANCIERA}

La rentabilidad de la sección de electricidad tuvo un comportamiento menos errático y más equilibrado que el resto de las secciones, en gran medida por ser más intensiva en capital. Dentro de su evolución se pueden distinguir cuatro etapas: En la primera etapa (1911-28), la rentabilidad fue bastante alta (próxima al 8 por cien) y superior, por ejemplo, a la obtenida por Ibérica o Pamplona (gráfico 3), en buena medida por las economías de alcance. El aumento de las tarifas eléctricas en 1919 dio lugar a un aumento de esta variable, pero no tuvo continuidad porque a partir de 1924 se realizaron importantes inversiones para la construcción de la central de Oroz-Betelu y el pantano de Irabia. En la segunda etapa (1929-40) este ratio se mantuvo en un nivel aceptable (entre el 6,5 y el 7,5 por cien), porque el fuerte esfuerzo de inversión (v. gr. Oroz-Betelu, Artozqui, Aoiz y Usoz) se tradujo, aunque con cierto retraso, en nuevas economías de escala. A pesar de ello, la situación económica se torció en la tercera etapa (1941-50) cuando la rentabi- 
GRÁFICO 3

RENTABILIDAD ECONÓMICA DE LA SECCIÓN DE ELECTRICIDAD DEL IRATI, ELECTRA PAMPLONA Y HIDROELÉCTRICA IBÉRICA. (1911-1960) (porcentaje)

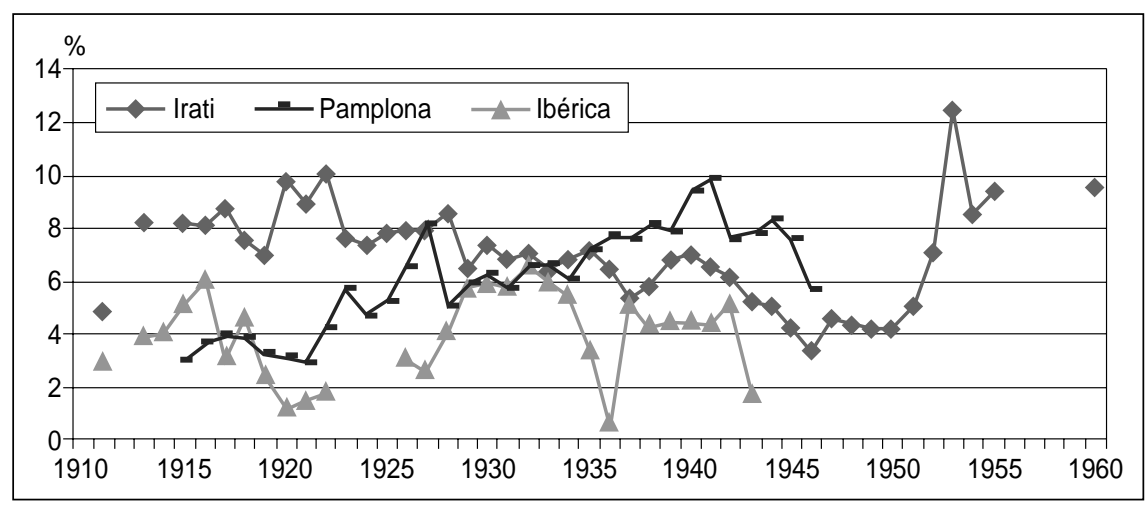

Fuentes: Cuadro A-1.

lidad descendió hasta el 4,2 por cien, esencialmente por los retrasos en hacer efectivos los beneficios de las nuevas inversiones productivas (Betolegui, Irabia, y Aoiz) y, en menor grado, por los negativos efectos de las sequías. Estas adversas circunstancias incrementaron la dependencia energética y funcional del Irati con relación a Iberduero y, en buena medida, explican su inmediato destino.

Sobre este particular, resulta muy pertinente la comparación de los beneficios unitarios del Irati respecto a los de Ibérica-Iberduero (gráfico 4), porque aclara en parte la conversión de la primera en filial de la segunda. Si hasta 1944 los beneficios unitarios de la primera compañía habían sido — gracias a sus reducidos costes y más altos precios de venta- francamente superiores a los de la segunda, a partir de entonces la tendencia se transformó radicalmente. Por otra parte, el estrangulamiento productivo de la segunda mitad de los años cuarenta supuso que, por primera vez, los costes unitarios del Irati compararan desfavorablemente respecto a los de Iberduero y, dado que las diferencias entre sus precios medios habían dejado de ser significativas, que también lo hicieran sus beneficios unitarios.

La integración en Iberduero se pudo demorar en el tiempo, porque, aparte de las razones citadas previamente, los aumentos de la capacidad de producción de los años 50 y el citado aumento de las tarifas (TTU) le permitieron al Irati un cierto respiro temporal en la última etapa (1951-60). Aún así, y a pesar de que los precios medios de la compañía fueron equiparables a los de empresas de gran tamaño, la dificultad para modificar la rígida estructura de costes se debe tener en cuenta para explicar la opción tomada finalmente por los gestores del Irati. 


\section{GRÁFICO 4 \\ ESTIMACIÓN COMPARADA ENTRE LOS INGRESOS (IUV), GASTOS (GUT) Y BENEFICIOS UNITARIOS (BU) DE HIDROELÉCTRICA IBÉRICA RESPECTO A LOS DEL IRATI (1905-1958)* (tantos por uno)}

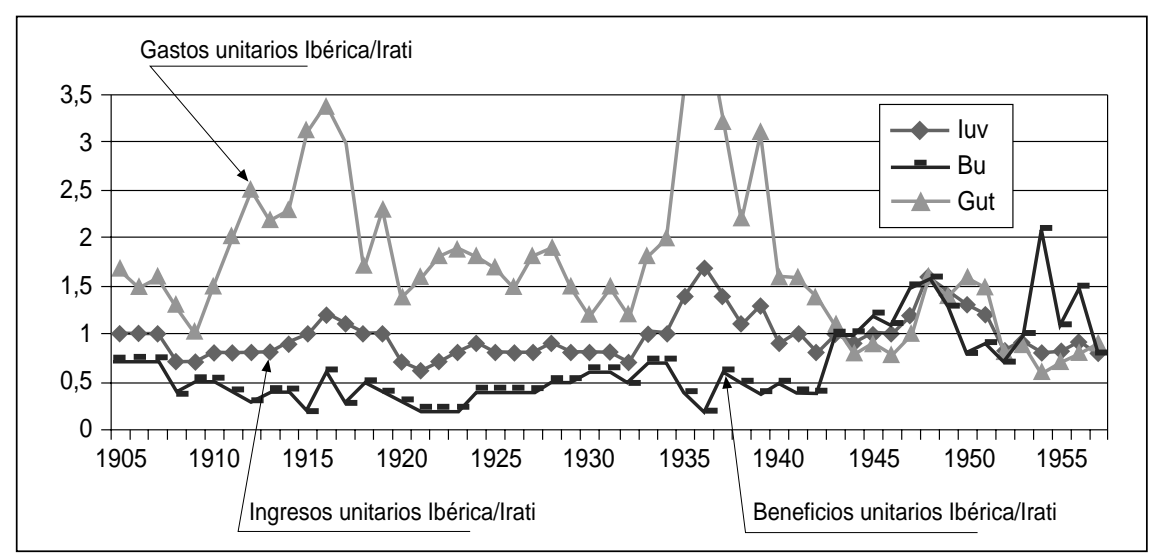

Fuentes: Cuadro A-1.

Notas: *Ingresos de explotación (ventas) y gastos totales.

Aunque nunca hay que olvidar que la vinculación a Iberduero venía justificada principalmente por la conjunción de varios temas interrelacionados: $a$ ) el estrangulamiento productivo de la sección de electricidad; $b$ ) la inviabilidad del conjunto empresarial (cada día más desestructurado por la mala marcha de las otras secciones), $\mathrm{y}$, sobre todo, $c$ ) la reordenación del mercado vasconavarro de electricidad en torno a Iberduero ${ }^{65}$.

Hay que añadir, con relación a la inviabilidad del conjunto empresarial, que el nivel de endeudamiento a partir de la Guerra Civil fue cada vez mayor, toda vez que la financiación dependía cada vez más de los capitales ajenos. De hecho, en su peor momento, entre 1953 y 1955, éstos suponían cerca del 40 por cien del pasivo, por lo que se estaba financiando parte del inmovilizado neto con capitales no permanentes. Fue entonces cuando los directivos del Irati se desprendieron del aserradero y destilería de Villaverde de Pontones (Santander - 1953—), se procedió al desmantelamiento del ferrocarril (1955), se amplió el capital social (1958) y se amortizaron las obligaciones emitidas en 1944. Aunque estas medidas corrigieron parcialmente el desequilibrio citado, no fueron suficientes para mostrar la viabilidad económica del conjunto empresarial integrado.

${ }^{65}$ Garrués (1994). 
En suma, estos años sirvieron para que los regentes del Irati se plantearan una solución definitiva al futuro de la empresa navarra más emblemática de la primera mitad del siglo Xx. Como se sabe, se optó por desgajar la sección forestal y química de la eléctrica. La primera pasó, en 1961, a conformar una nueva empresa, El Irati Forestal, y la segunda, a depender desde 1958 de Iberduero.

\section{RESUMEN Y CONCLUSIONES}

El desarrollo del Irati es un buen ejemplo de diferentes estrategias empresariales que se esconden bajo las primeras fases del desarrollo eléctrico español y, a su vez, su estudio resulta un buen campo de pruebas para formular nuevas preguntas sobre los factores y condicionamientos de los procesos regionales de industrialización. En sus primeros años resultó ser una firma singular porque representó una de las primeras empresas industriales en torno a la explotación moderna de la madera en España. Consiguió integrar, merced a las nuevas posibilidades que concedía la electricidad en el terreno industrial y de la tracción, varias actividades fabriles: serrerías, destilerías, ferrocarril eléctrico y la comercialización de electricidad de origen hidroeléctrico a alta tensión. El nacimiento de Irati muestra, además, cómo en la Navarra de principios del siglo XX surgió un grupo de empresarios que no escatimaron esfuerzos a la hora de promover iniciativas industriales, movilizar los capitales de la burguesía autóctona y foránea (indiana) y utilizar la más moderna tecnología, en pro de sacar buen rendimiento a los capitales invertidos. Su dinamismo posterior puede resultar también un buen ejemplo de los cambios que, aunque tímidos, se fueron fraguando en algunas regiones poco industrializadas ante las nuevas oportunidades de negocio abiertas con la Segunda revolución tecnológica y la mayor integración de los mercados ${ }^{66}$. Además, la experiencia adquirida por sus directivos y accionistas en el mundo de la empresa debió contribuir — como activo intangible — a mejorar la cultura y cohesión de las primeras redes empresariales de la burguesía navarra ${ }^{67}$.

Pese a que la sección de electricidad del Irati compartió con las otras dos eléctricas de Pamplona - Arteta y Pamplona - la misma condición tecnológica (hidroeléctrica), unos gestores inicialmente dinámicos y un mismo mercado

${ }^{66}$ Sobre la integración económica y la localización industrial española véase, Tirado, Palucie \& Pons (2002).

${ }^{67}$ En algunas regiones periféricas españolas a finales del siglo XIX y principios del XX es perceptible - aunque no siempre fácilmente demostrable — cómo los incipientes grupos empresariales entretejen mecanismos informales de aprendizaje como medio de reducir costes de transacción ante cambiantes condiciones de la tecnología y los mercados. Para conocer adecuadamente las diferentes estrategias de las empresas familiares en la capacitación y transmisión de conocimientos, véase Fernández \& Puig (2004). 
(Pamplona), su desarrollo fue bien diferente. La trayectoria del Irati fue muy activa. Contrariamente a la postura de Arteta, la formación del oligopolio autorregulado por las propias empresas (1915) no minó su política expansiva. De hecho, sus decisiones de producción siempre se anticiparon a la evolución de la demanda hasta los años cuarenta. Sin embargo, la leve recuperación del consumo (tras los primeros años de la Guerra Civil y la incorporación de Arteta -1942-), las dificultades para adquirir el material eléctrico para su tercer plan de construcciones y los efectos de las sequías colocaron a la compañía en una situación crítica. De hecho, aunque ésta se fue capeando conforme se hacían efectivos los nuevos incrementos de potencia citados, la firma estableció restricciones al consumo y tuvo, primero, que comprar energía a Iberduero y, más tarde (1959), ser absorbida por ésta.

Este camino, pese a las singularidades que se quiera, tiene su mayor interés en cuanto que coincide en el tiempo y en las formas con los descritos por otras muchas pequeñas y medianas eléctricas españolas. Y es que la negra coyuntura del primer franquismo produjo un fenómeno curioso. Por un lado, la situación de escasez y restricciones permitieron en algunas regiones la subsistencia de sistemas eléctricos tradicionales más allá de lo que su propio ciclo vital podía aventurar. Pero, al mismo tiempo, su debilidad productiva, financiera y funcional para afrontar la crisis económica les dejó desarmados a la hora de negociar una salida digna del mercado u ocupar una nueva posición como distribuidoras-comercializadoras independientes. Esto fue en beneficio, claro está, de las grandes compañías que reforzaron su posición hegemónica en sus mercados naturales ante la nueva fase de desarrollo del sector, esencialmente mediante el aumento de la escala de operaciones en el ámbito de la producción (grandes centrales hidroeléctricas, térmicas y nucleares) y de la distribución (interconexión del mercado eléctrico peninsular), así como en el orden institucional, interno (preparación técnica y estructura organizativa) y externo (UNESA - 1944-).

Pero antes de que todo esto aconteciera, la concurrencia de varias empresas en el mercado eléctrico de Pamplona debió contribuir positivamente a su proceso de electrificación. La aparición en 1904 de Electra Aoiz en la capital redujo las ventajas con las que inicialmente contaba Arteta y debió endurecer la competencia, especialmente a partir de que se transformara aquélla en Irati (1910). Sin embargo, como esta compañía prefirió consolidar su complejo industrial, participó también en el cártel eléctrico de Pamplona (1915), entre otras cosas, además, porque no limitaba sus posibilidades de crecimiento. Durante los primeros años del oligopolio corporativo, no obstante, las relativas ventajas de los consumidores de Pamplona respecto a los precios del suministro eléctrico se fueron disipando. De un lado, la construcción de grandes centrales hidroeléctricas posibilitó que los precios de algunos mercados fueran inferiores a los de esta ciudad, y, de otro, los precios en la capital navarra conocieron una significativa subida. 
El estudio de los precios medios desagregados por segmentos de consumo, empero, muestra que las diferencias entre los precios del Irati y los ofertados por Ibérica (la mayor eléctrica vasca) a la altura de 1930 no fueron tan evidentes como en principio pudiera pensarse y, sobre todo, constata la independencia funcional y económica que algunas industrias autoproductoras tuvieron frente a las clásicas eléctricas comerciales. El relativo equilibrio que manifestó el cártel eléctrico se rompió cuando Pamplona, debido a sus estrangulamientos productivos, llegó a un acuerdo de suministro con Ibérica (1934), Arteta se convirtió en filial del Irati (1942) y, algo más tarde, ésta inicio conversaciones con Ibérica (una vez que la firma vizcaína absorbió a Pamplona -1944-) para restablecer un nuevo equilibrio de fuerzas en el mercado pamplonés. Estas conversaciones se convirtieron a la postre en largas negociaciones para integrar al Irati dentro del sistema eléctrico de Iberduero. Entretanto, el estancamiento de los precios nominales entre los años veinte y el establecimiento de las TTU (1953) atenuó eventuales desventajas comparativas previas con relación al proceso de electrificación de la capital navarra.

Por último, la situación económica y financiera del Irati fue bastante satisfactoria para sus directivos y accionistas. La buena marcha de su sección eléctrica, por su parte, corrobora la viabilidad económica y funcional que algunas compañías autoproductoras-comerciales tuvieron durante las primeras fases del desarrollo eléctrico español. Al mismo tiempo, la pérdida de rentabilidad posterior refleja la situación crítica atravesada por los sistemas eléctricos tradicionales, cuando, incapaces de dar plena satisfacción al crecimiento de la demanda, se convirtieron en una presa fácil de los sistema eléctricos integrados (en este caso de Iberduero).

\section{BIBLIOGRAFÍA}

Amigo, P. (1991): «La industria eléctrica en Valladolid (1887-1930): características fundamentales», en Yun, B. (1991), Estudios sobre capitalismo agrario, crédito e industria en Castilla. Valladolid: Junta de Castilla y León, pp. 203-234.

ANCIL (1911): «Ferrocarril eléctrico y explotaciones hidroeléctricas de "El Irati"». Revista La Energía Eléctrica, 10 de septiembre, año VIII, pp. 316-321.

ANTOLín, F. (1988): «Un servicio público con escasa intervención: los primeros cuarenta años de electricidad en España». Economía Industrial, 262, julio-agosto, pp. 27-38.

- (1989): «Hidroeléctrica Ibérica y la electrificación del País Vasco». Economía Pública, 4, pp. 107-130.

- (1999a): «Samuel Insull y Juan Urrutia, dos empresarios de principios de siglo. La formación de la gran empresa eléctrica española en un contexto comparativo», en A. Carreras; P. Pascual; D. Reher, y C. Sudrà (eds.), Doctor Jordi Nadal: La industrialización y el desarrollo económico de España. Barcelona: Universidad de Barcelona, pp. 1356-1377. 
- (1999b): «Iniciativa privada y la política pública en el desarrollo de la industria eléctrica en España. La hegemonía de la gestión privada, 1875-1950». Revista de Historia Económica, 2, pp. 411-445.

ARAQUiSTAIN, I. (1946): «Todas las industrias guipuzcoanas electrificadas se han inscrito en la "Caja de Compensación de Paro por Escasez de Fluido Eléctrico"». Economía Vascongada, año II, 12 febrero, pp. 50-53.

ARIZKUN, A. (2001): «Navarra: de la especialización agraria a la industrialización», en Germán; Llopis; Maluque, y Zapata (eds.), Historia económica regional de España siglos XIX y XX. Barcelona: Crítica, pp. 125-152.

Aubanell, A. M. (1992): «La competencia en la distribución de electricidad en Madrid, 1890-1913». Revista de Historia Industrial, 2, pp. 143-171.

- (2000): «Estrategia industrial y estrategia financiera de la Sociedad Hidroeléctrica Española en el primer tercio del siglo XX». Revista de Historia Industrial, 17, pp. 153185.

Balzani, R., y Altri (1992): Storia dell'Industria elettrica in Italia. Le Origini, 18821914. Roma: Laterza.

BARONE, G., y ALtri (1993a): Storia dell'Industria elettrica in Italia. Il potenziamento tecnico e finanziario, 1914-1925. Roma: Laterza.

- (1993b): Storia dell'Industria elettrica in Italia. Espansione e Oligopolio 1926-1945. Roma: Laterza.

BARTolomé, I. (1995): «Los límites de la hulla blanca en vísperas de la Guerra Civil: un ensayo de interpretación». Revista de Historia Industrial, 7, pp. 109-140.

Bases para un convenio entre «El Irati, S.A.», y «Conducción de Aguas de Arteta, S.A.», de una parte, e «Iberduero, S.A.» y «Fuerzas Eléctricas de Navarra, S.A.», de otra (1953). Pamplona: Archivo de Iberdrola.

Bernal, A.-M. (1993): «Ingenieros-empresarios en el desarrollo eléctrico español: Mengemor, 1904-1951». Revista de Historia Industrial, 3, pp. 93-126.

Boletín de la CÁmara Oficial de Comercio y de la Industria de Navarra (1901). Pamplona: Cámara Navarra.

Caron, F., y CARDot, F. (1991): Histoire Générale de L'électricité en France. Espoirs et Conquêtes, 1881-1918, t. I. Paris: Fayard.

CARreras, A., y TAfunell (1993): «La gran empresa en España (1917-1974)». Revista de Historia Industrial, 3, pp. 127-175.

CAsson, M. (1984): «The theory of vertical integration: A survey and synthesis». Journal of Economics Studies. The firm its activities \& evolution, vol. 11 (2), pp. 3-43.

Castiella, M. (1989): El Irati S.A. Historia de una empresa navarra, (tesis inédita). Pamplona: Universidad de Navarra.

CATALÁn, J. (1995): La economía española y la segunda guerra mundial. Barcelona: Ariel.

CAYón, F. (2001): «Electricidad e historia: la perspectiva de un siglo». Revista de Historia Transportes, Servicios y Telecomunicaciones, 1, pp. 113-133.

- (2002): Hidroeléctrica Española: un análisis de sus primeros años de actividad (19071936). Revista de Historia Económica, 2, pp. 301-334.

ChAndLer, A. D. (1977): The Visible Hand. The managerial revolution in American business. London: Harvard University Press.

- (1990): Scale and scope: The dynamics of industrial capitalism. Cambridge: Harvard University Press. 
Chandler, A. D., y DAEMs, H. (1980): Managerial Hierarchies. Comparative Perspectives on the Rise of the Modern Industrial Enterprise. London: Harvard University Press.

Chandler, A. D.; Hikino, T., y Amatori, F. (eds.) (1997): Big business and the Wealth of Nations. Cambridge: Cambridge University Press.

Colli, A.; Fernández, P., y Rose, M. B. (2003): «National determinants of family firm development? Family firms in Britain, Spain, and Italy in the Nineteenth and Twentieth centuries». Enterprise \& Society. The International Journal of Business History, March, vol. 4, núm. 1, pp. 28-64.

Comín, F., y Martín AcEÑA, P. (1996): «Rasgos históricos de las empresas en España. Un panorama». Revista de Economía Aplicada, 12, pp.75-123.

Comisión del Sistema ElÉctrico Nacional (1997): Comparación de los precios de la electricidad en el entorno europeo. Madrid: Dirección de Regulación.

FERnÁndez, P., y Puig, N. (2004): «Knowledge and training in family firms of the European periphery: Spain in the eighteenth to twentieth centuries». Business History, vol. 46, núm. 1 (January), pp. 79-99.

GALlEGo, E. (1915): «Precios a que se vende el kilovatio de electricidad para alumbrado y fuerza motriz en las principales poblaciones de España». Revista La Energía Eléctrica, 10 de noviembre, p. 156.

GARRUÉs, J. (1994): «La formación del mercado eléctrico Vasconavarro e Hidroeléctrica Ibérica», en P. Martín Aceña, y M. Gárate (eds.), Economía y Empresa en el Norte de España (Una aproximación histórica). San Sebastián: Universidad del País Vasco, pp. 185-213.

- (1996): El proceso de industrialización navarro: el desarrollo del sector eléctrico (1888-1980). Tesis doctoral, Facultad de Ciencias Económicas y Empresariales, Universidad de Granada (microforma, 1999).

- (1997a): «El desarrollo del sistema eléctrico navarro, 1888-1986». Revista de Historia Industrial, 11, pp. 73-117.

- (1997b): «La electricidad en los procesos de industrialización regional: el caso navarro». Revista del Instituto Gerónimo de Uztáriz, 13, pp. 83-106.

- (1997c): «El Irati, Compañía general de maderas, fuerzas hidráulicas y tranvía eléctrico de Navarra, 1904-1961», 9701, WP. Madrid: Fundación de Empresa Pública.

- (2006): «Del lento despertar de la empresa industrial navarra y el acelerado tránsito al capitalismo gerencial. Una visión a largo plazo», en C. Y. Manera, y J. L. García Ruiz (coords.), Historia empresarial de España. Una perspectiva regional. Madrid: Lid.

GERMÁn, L. (ed.) (1990): ERZ (1910-1990). El desarrollo del sector eléctrico en Aragón. Zaragoza: Instituto Fernando el Católico-ERZ.

Gómez Mendoza, A. (ed.) (2000): De mitos y milagros: el Instituto Nacional de Autarquía (1941-1963). Barcelona: Universidad de Barcelona.

HanNAH, L. (1979): Electricity before Nationalisation. A Study of the development of the electricity supply industry in Britain to 1948. London: The Macmillan Press.

- (1982): Engineers, Managers and Politicians: The First Fifteen Years of Nationalised Electricity Supply in Britain 1948-1962. London: Macmillan and Johns Hopkins University Press.

- (1994): Delusions of durable dominance or the invisible hand strikes back. A critique of the new orthodoxy in international comparative business history, 1880-1980s. Manuscript. 
— (1997): Marshall's «Trees» and the global «forest»: were «gigant rewoods» different? Discussion Paper núm. 318. Centre for Economic Performance (London School of Economics), January.

Hughes, T. P. (1983): Networks of Power: Electrification in Western Society, 1880-1930. Electrification in Western Society, 1880-1930. Meryland:The Johns Hopkins University Press.

IBERDUERo (1968): Datos para la historia de Hidroeléctrica Ibérica. Documento núm. 23.785. Bilbao: Archivo de Iberdrola.

IMPUESTO DE CONTRIBUCIÓN INDUSTRIAL Y DEL COMERCIO (1917 y 1927): Partes mensuales de producción de electricidad. Pamplona: Archivo Administrativo del Gobierno de Navarra.

Instituto NaCiOnAl de Estadística (varios años): Anuario Estadístico de España. Madrid.

JEREMY, D. (2002): «Business History and Strategy», en A. M. Pettigrew; H. Thomas, y R. Whittington (eds.), Handbook of Strategy and Mangement. London: SAGE Publications.

LéVy-Leboyer, M., y Morsel, H. (1994): Histoire Générale de L'électricité en France. L'interconnexion et le marché, 1919-1946, t. II. Paris: Fayard.

Libros de Sociedades del Registro Mercantil de NaVArRa (1886-1955). Pamplona: Registro Mercantil de Pamplona.

Maluquer de Motes, J. (1983): «L'electricitat», en NAdal, J.; MaluQuer, J.; Carreras, A., y Sudriá, C., Producció i consum d'energia en el creixement econòmic modern: el cas català. Barcelona, cap. 6 (Inédito).

- (1987): «L'électricité, facteur de développement économique en Espagne: 1900-1936», en F. Cardot (ed.), pp. 57-67.

- (1991): «Precios, salarios y beneficios. La distribución funcional de la renta», en Carreras (coord.), Estadísticas Históricas de España, siglos XIX y XX. Barcelona: Fundación Banco Exterior, pp. 497-532.

- (1992): «Los pioneros de la segunda revolución industrial en España: la Sociedad Española de Electricidad (1881-1894)». Revista de Historia Industrial, 2, pp. 121-141.

MEMoria Técnica El Qquinquenio 1935-1939 (1940). Bilbao: Archivo de Iberdrola.

Ministerio DE FoMENTO (1910): Estadística de la energía eléctrica a fines de 1910. Madrid: Dirección General de Agricultura, Industria y Comercio.

MINISTERIO DE INDUSTRIA Y COMERCIO (varios años): Estado actual de la producción y distribución de la energía eléctrica en España. Madrid: Consejo (Superior) de Industria.

NúÑEZ, G. (1993): La Sevillana de Electricidad y la promoción multinacional en el sector electrotécnico. Granada: Nemesis.

- (1994a): «Origen e integración de la industria eléctrica en Andalucía y Badajoz», en Alcaide, J.; Bernal, A. M.; García Enterría, E., Compañía Sevillana de Electricidad. Cien años de historia. Sevilla: Fundación Sevillana de Electricidad, pp. 127-159.

- (1994b): «Cien Años de la evolución institucional en el sector eléctrico en España», G. Núñez, y L. Segreto. (eds.) (1994): Introducción a la Historia de la Empresa en España. Madrid: Abacus, pp. 221-252.

- (1995): «Empresas de producción y distribución de electricidad en España (18781953)». Revista de Historia Industrial, 7, pp. 39-80. 
PASSER, H. C. (1988): The electrical manufactures, 1875-1900: a study in competition, entrepreneurship, technical change and economis growth. Salem: Ayer Company Publishers.

Revista La Energía ElÉCtrica (1908a): «Fusión de eléctricas de Bilbao», año X, 7, 10 de marzo, pp. 116-117.

- (1908b): «Trabajos de Fusión», año X, 16, 25 de agosto, p. 80.

- (1912): «Las Eléctricas en Vitoria», año XIV, 6, 25 de marzo, p. 122.

- (1913): «Las compañías eléctricas de Valencia», año XV, 14, 25 de julio, pp. 272.

Rose, M. H. (1995): Cities of Light and Heat: Domesticating Gas and Electricity in Urban America. University Park, Pa.: The Pennsylvania State University Press.

Sindicato Vertical (o Nacional) de Agua, Gas y Electricidad. Servicio Sindical de Estadística (1944-1964): Datos estadísticos técnicos de las Centrales Eléctricas Españolas. Madrid.

SUDRIÀ, C. (1987a): «Un factor determinante: la energía», en J. Nadal; A. Carreras, y C. Sudrià (comps.), pp. 313-363.

- (1987b): «Les restrictions de la consommation d'électricité en Espagne pendant l'après guerre: 1944-1954», en F. CARDOT (ed.), pp. 425-435.

- (1989): «L'energia: de l'alliberament hidroeléctric a la dependencia petroliera», en Nadal; Maluquer; Sudrià, y Cabana (eds.), Història Econòmica de la Calalunya Contemporània, vol. 5. Barcelona: Enciclopedia Catalana, pp. 211-293.

- (1990): «La industria eléctrica y el desarrollo económico de España», en J. L. García Delgado (ed.), pp. 147-184.

SudRià, C., y ANTOLÍN, F. (1994): «Policy and performance in the Spanish electricity utility industry, 1939-1983: from rationing to excess capacity», en A. Beltrán, y H. Morsel (eds.), Electricity generation and supply: regulation, market, competition. International comparisons. Eleventh International Economic History Congress. Milan: Università Bocconi.

TENA, A. (1988): «Importación, niveles de protección y producción del material eléctrico en España (1890-1935)». Revista de Historia Económica, 2, pp. 341-371.

TIRAdo, A.; PolUZIE, E., y PONS, J. (2002): «Economic integration and industrial location: the case of Spain before Wold War I». Journal of Economic Geography, 2, pp. 343-363.

United NATIONS (1996): Long-term historical change in the forest resource. Case studies of Finland, France, Great Britain, Greece, Hungary, The Netherlands, Sweden and the United States of America. Geneva Timber and Forest Study Papers. United Nations Economic Commission for Europe: New York and Geneva.

Williams, M. (1989): Americans and their forests. A historical geography. New York: Cambridge University Press.

YesARES, R. (1905): Anuario de electricidad. Madrid.

ZAPATA, S. (2001): «La madera en España (c. 1850-c. 1950)». Revista de Historia Económica, 2, pp. 287-343. 
JOSEAN GARRUÉS IRURZUN URRUTIA

CUADRO A-1

PRODUCCIÓN, POTENCIA, RENTABILIDAD

Y BENEFICIOS UNITARIOS DEL IRATI EN PERSPECTIVA COMPARADA (GWh, MW, \% y Cts/kWh)

\begin{tabular}{|c|c|c|c|c|c|c|c|c|c|c|c|}
\hline \multirow{3}{*}{ Año } & Producción & Potencia & \multicolumn{3}{|c|}{ Rentabilidad } & \multicolumn{3}{|c|}{ Relación Ibérica/Irati } & \multicolumn{3}{|c|}{$\begin{array}{c}\text { Precios/Ingresos } \\
\text { medios (medias } \\
\text { móviles de tres años) }\end{array}$} \\
\hline & \multicolumn{2}{|c|}{ EIr } & EIr & EP & HI & Iuv & Gu & Bu & EIr & HI & CAA \\
\hline & GWh & MW & \multicolumn{3}{|c|}{$\%$} & \multicolumn{3}{|c|}{ Tanto por uno } & \multicolumn{3}{|c|}{ Cts/kWh } \\
\hline 1904 & 1,32 & 0,4 & - & - & - & - & - & - & - & - & - \\
\hline 1905 & 1,63 & 0,6 & - & - & - & 1,1 & 1,3 & 0,9 & 5,5 & 6,1 & 7,0 \\
\hline 1906 & 2,62 & 0,6 & - & - & - & 1,0 & 1,7 & 0,7 & 5,5 & 5,6 & 7,0 \\
\hline 1907 & 2,40 & 0,6 & - & - & - & 1,0 & 1,5 & 0,7 & 5,5 & 5,4 & 7,0 \\
\hline 1908 & 2,59 & 0,6 & - & - & - & 1,0 & 1,6 & 0,7 & 5,5 & 5,4 & 7,1 \\
\hline 1909 & 2,79 & 0,9 & - & - & - & 0,7 & 1,3 & 0,4 & 5,5 & 3,8 & 7,2 \\
\hline 1910 & 3,21 & 1,8 & - & - & - & 0,7 & 1,0 & 0,5 & 5,5 & 3,8 & 7,2 \\
\hline 1911 & 5,76 & 1,8 & 4,9 & - & 3,0 & 0,8 & 1,5 & 0,5 & 5,0 & 3,9 & 7,1 \\
\hline 1912 & 6,05 & 1,8 & - & - & - & 0,8 & 2,0 & 0,4 & 5,0 & 3,8 & 6,9 \\
\hline 1913 & 6,19 & 1,8 & 8,2 & - & 3,9 & 0,8 & 2,5 & 0,3 & 5,0 & 4,0 & 6,8 \\
\hline 1914 & 6,34 & 1,8 & - & - & 4,0 & 0,8 & 2,2 & 0,4 & 5,0 & 4,2 & 6,8 \\
\hline 1915 & 6,49 & 1,8 & 8,2 & 3,0 & 5,1 & 0,9 & 2,3 & 0,4 & 5,0 & 4,3 & 7,0 \\
\hline 1916 & 6,69 & 1,8 & 8,1 & 3,6 & 6,1 & 1,0 & 3,1 & 0,2 & 5,0 & 4,8 & 7,3 \\
\hline 1917 & 6,31 & 1,8 & 8,8 & 3,9 & 3,1 & 1,2 & 3,4 & 0,6 & 5,5 & 6,5 & 7,8 \\
\hline 1918 & 5,73 & 1,8 & 7,6 & 3,8 & 4,6 & 1,1 & 3,0 & 0,3 & 6,0 & 6,5 & 8,7 \\
\hline 1919 & 6,17 & 1,8 & 7,0 & 3,2 & 2,4 & 1,0 & 1,7 & 0,5 & 6,0 & 5,9 & 9,9 \\
\hline 1920 & 6,87 & 1,8 & 9,8 & 3,1 & 1,2 & 1,0 & 2,3 & 0,4 & 6,9 & 7,1 & 10,5 \\
\hline 1921 & 6,00 & 1,8 & 9,0 & 2,9 & 1,5 & 0,7 & 1,4 & 0,3 & 8,2 & 5,7 & 10,8 \\
\hline 1922 & 6,06 & 2,4 & 10,1 & 4,2 & 1,8 & 0,6 & 1,6 & 0,2 & 8,5 & 5,4 & 10,7 \\
\hline 1923 & 6,60 & 2,4 & 7,7 & 5,7 & - & 0,7 & 1,8 & 0,2 & 8,3 & 5,9 & 10,9 \\
\hline 1924 & 7,10 & 2,4 & 7,4 & 4,7 & - & 0,8 & 1,9 & 0,2 & 7,8 & 6,3 & 11,4 \\
\hline 1925 & 7,85 & 2,4 & 7,8 & 5,2 & - & 0,9 & 1,8 & 0,4 & 7,6 & 6,5 & 11,4 \\
\hline 1926 & 7,14 & 2,4 & 7,9 & 6,5 & 3,1 & 0,8 & 1,7 & 0,4 & 8,3 & 6,5 & 11,2 \\
\hline 1927 & 7,54 & 2,4 & 7,9 & 8,1 & 2,6 & 0,8 & 1,5 & 0,4 & 8,1 & 6,2 & 10,8 \\
\hline 1928 & 7,99 & 2,9 & 8,6 & 5,0 & 4,1 & 0,8 & 1,8 & 0,4 & 8,0 & 6,4 & 11,1 \\
\hline 1929 & 8,43 & 2,9 & 6,4 & 5,9 & 5,8 & 0,9 & 1,9 & 0,5 & 8,0 & 7,0 & 11,8 \\
\hline 1930 & 9,60 & 3,7 & 7,4 & 6,3 & 6,0 & 0,8 & 1,5 & 0,5 & 8,5 & 6,8 & 11,9 \\
\hline 1931 & 10,05 & 3,7 & 6,8 & 5,7 & 5,8 & 0,8 & 1,2 & 0,6 & 9,2 & 6,9 & 11,2 \\
\hline 1932 & 12,26 & 3,7 & 7,0 & 6,5 & 6,6 & 0,8 & 1,5 & 0,6 & 7,8 & 6,6 & 10,9 \\
\hline 1933 & 10,66 & 3,7 & 6,4 & 6,6 & 6,1 & 0,7 & 1,2 & 0,5 & 9,3 & 6,7 & 11,3 \\
\hline 1934 & 10,76 & 3,7 & 6,8 & 6,1 & 5,5 & 1,0 & 1,8 & 0,7 & 9,3 & 9,3 & 12,1 \\
\hline 1935 & 12,92 & 4,4 & 7,2 & 7,2 & 3,4 & 1,0 & 2,0 & 0,7 & 8,4 & 8,7 & 12,2 \\
\hline 1936 & 16,96 & 4,4 & 6,4 & 7,7 & 0,6 & 1,4 & 3,7 & 0,4 & 6,3 & 9,1 & 11,7 \\
\hline 1937 & 14,23 & 4,4 & 5,3 & 7,7 & 5,2 & 1,7 & 4,6 & 0,2 & 6,3 & 10,8 & 11,5 \\
\hline 1938 & 14,12 & 4,4 & 5,8 & 8,1 & 4,3 & 1,4 & 3,2 & 0,6 & 6,8 & 9,6 & 11,4 \\
\hline 1939 & 14,50 & 4,4 & 6,8 & 7,9 & 4,5 & 1,1 & 2,2 & 0,5 & 7,9 & 8,6 & - \\
\hline 1940 & 14,73 & 4,4 & 7,0 & 9,4 & 4,5 & 1,3 & 3,1 & 0,4 & 6,5 & 8,3 & - \\
\hline 1941 & 14,83 & 4,4 & 6,5 & 9,9 & 4,4 & 0,9 & 1,6 & 0,5 & 9,3 & 8,6 & - \\
\hline
\end{tabular}


CUADRO A-1 (Cont.)

\begin{tabular}{|c|c|c|c|c|c|c|c|c|c|c|c|}
\hline \multirow{3}{*}{ Año } & Producción & Potencia & \multicolumn{3}{|c|}{ Rentabilidad } & \multicolumn{3}{|c|}{ Relación Ibérica/Irati } & \multicolumn{3}{|c|}{$\begin{array}{c}\text { Precios/Ingresos } \\
\text { medios (medias } \\
\text { móviles de tres años) }\end{array}$} \\
\hline & \multicolumn{2}{|c|}{ EIr } & EIr & EP & HI & Iuv & Gu & Bu & EIr & HI & CAA \\
\hline & GWh & MW & \multicolumn{3}{|c|}{$\%$} & \multicolumn{3}{|c|}{ Tanto por uno } & \multicolumn{3}{|c|}{ Cts $/ \mathbf{k W h}$} \\
\hline 1942 & 15,00 & 4,4 & 6,2 & 7,7 & 5,1 & 1,0 & 1,6 & 0,4 & 10,0 & 9,6 & - \\
\hline 1943 & 15,28 & 4,4 & 5,2 & 7,8 & 1,7 & 0,8 & 1,4 & 0,4 & 11,0 & 9,1 & - \\
\hline 1944 & 16,26 & 4,4 & 5,0 & 8,3 & - & 1,0 & 1,1 & 1,0 & 11,3 & 11,6 & - \\
\hline 1945 & 16,19 & 4,4 & 4,2 & 7,6 & - & 0,9 & 0,8 & 1,0 & 11,9 & 11,0 & - \\
\hline 1946 & 15,82 & 5,1 & 3,4 & 5,7 & - & 1,0 & 0,9 & 1,2 & 11,8 & 12,3 & - \\
\hline 1947 & 20,31 & 6,2 & 4,6 & - & - & 1,0 & 0,8 & 1,1 & 12,7 & 12,4 & - \\
\hline 1948 & 23,73 & 6,2 & 4,4 & - & - & 1,2 & 1,0 & 1,5 & 12,8 & 15,2 & - \\
\hline 1949 & 23,38 & 6,2 & 4,2 & - & - & 1,6 & 1,6 & 1,6 & 14,0 & 22,3 & - \\
\hline 1950 & 22,98 & 8,6 & 4,2 & - & - & 1,4 & 1,4 & 1,3 & 16,1 & 22,1 & - \\
\hline 1951 & 27,94 & 8,6 & 5,0 & - & - & 1,3 & 1,6 & 0,8 & 15,8 & 19,9 & - \\
\hline 1952 & 31,73 & 8,6 & 7,1 & - & - & 1,2 & 1,5 & 0,9 & 16,5 & 20,4 & - \\
\hline 1953 & 30,02 & 8,6 & 12,5 & - & - & 0,8 & 0,8 & 0,7 & 31,6 & 24,6 & - \\
\hline 1954 & 26,58 & 11,2 & 8,6 & - & - & 0,9 & 0,9 & 1,0 & 32,5 & 30,2 & - \\
\hline 1955 & 24,70 & 11,2 & 9,4 & - & - & 0,8 & 0,6 & 2,1 & 39,1 & 29,7 & - \\
\hline 1956 & 29,58 & 11,2 & - & - & - & 0,8 & 0,7 & 1,1 & 36,9 & 30,1 & - \\
\hline 1957 & 30,24 & 11,2 & - & - & - & 0,9 & 0,8 & 1,5 & 46,6 & 43,7 & - \\
\hline 1958 & 31,02 & 11,2 & - & - & - & 0,8 & 0,9 & 0,8 & 51,7 & 43,6 & - \\
\hline 1959 & 34,57 & 11,2 & - & - & - & - & - & - & - & - & - \\
\hline 1960 & 35,31 & 11,2 & 9,6 & - & - & - & - & - & - & - & - \\
\hline 1961 & 34,02 & 11,2 & - & - & - & - & - & - & - & - & - \\
\hline
\end{tabular}

Fuentes: Memorias anuales de la Junta General de Accionistas de Irati, Hidroeléctrica Ibérica/Iberduero y Electra Pamplona.

Notas: Los precios medios (Ingresos de la venta de electricidad/ $\mathrm{kWh}$ producidos) se han elaborado a partir de los cuadros de producción y cuentas de resultados de Irati, Arteta e Iberduero (1968)

La rentabilidad económica resulta de dividir los Beneficios antes de impuestos entre el Activo total. Clave: EIr (El Irati); HI (Hidroeléctrica Ibérica); EP (Electra Pamplona); y CAA (Conducción de Aguas Arteta).

El factor de carga (FC) se obtiene de la siguiente fórmula: producción anual/(8.760* potencia máxima disponible). 
CUADRO A-2

DISTRIBUCIÓN DE LA ELECTRICIDAD SUMINISTRADA POR IRATI (1917-1961) (Miles de abonados y GWh)

\begin{tabular}{|c|c|c|c|c|c|c|c|c|c|c|c|c|}
\hline \multirow{4}{*}{ Año } & \multirow{3}{*}{ D } & \multirow{3}{*}{$\mathbf{P}$} & \multirow{3}{*}{ Ad } & \multicolumn{8}{|c|}{ Vendido en el mercado de: } & \multirow{3}{*}{ Pérd. } \\
\hline & & & & \multirow{2}{*}{ Arteta } & \multicolumn{7}{|c|}{ Irati } & \\
\hline & & & & & \multicolumn{2}{|c|}{ Consumo } & \multicolumn{2}{|c|}{ Doméstico } & \multicolumn{2}{|c|}{ Industrial } & \multirow{2}{*}{$\begin{array}{l}\text { FFCC } \\
\text { GWh }\end{array}$} & \\
\hline & Gwh & Gwh & Gwh & Gwh & $\begin{array}{l}\text { Miles } \\
\text { Abon. }\end{array}$ & Gwh & $\begin{array}{l}\text { Miles } \\
\text { Abon. }\end{array}$ & Gwh & $\begin{array}{l}\text { Miles } \\
\text { Abon. }\end{array}$ & Gwh & & GWh \\
\hline $1917^{*}$ & 6,3 & 6,3 & - & - & - & 5,3 & - & 2,0 & - & 2,5 & 0,76 & 1,0 \\
\hline $1927 *$ & 7,5 & 7,5 & - & - & - & 6,3 & - & 3,1 & - & 2,4 & 0,85 & 1,2 \\
\hline 1944 & 16,3 & 16,3 & & 1,5 & 5,1 & 8,2 & 4,5 & 2,9 & 0,53 & 4,5 & 0,75 & 6,6 \\
\hline 1949 & 23,4 & 23,4 & 0,003 & 3,9 & 5,9 & 10,8 & 5,4 & 4,2 & 0,49 & 6,3 & 0,29 & 8,7 \\
\hline 1950 & 25,6 & 23,0 & 2,6 & 3,1 & 5,9 & 12,6 & 5,4 & 4,5 & 0,45 & 7,7 & 0,42 & 9,8 \\
\hline 1953 & 30,0 & 30,0 & - & 5,2 & 6,4 & 15,5 & 5,9 & 4,8 & 0,52 & 10,3 & 0,41 & 9,3 \\
\hline 1954 & 26,6 & 26,6 & - & 4,8 & 6,5 & 14,8 & 6,0 & 5,0 & 0,51 & 9,4 & 0,36 & 7,0 \\
\hline 1955 & 24,9 & 24,7 & 0,2 & 4,6 & 6,3 & 14,0 & 5,5 & 5,6 & 0,71 & 8,1 & 0,37 & 6,3 \\
\hline 1956 & 29,6 & 29,6 & - & 4,4 & 6,5 & 16,4 & 6,0 & 6,0 & 0,52 & 10,2 & 0,16 & 8,8 \\
\hline 1957 & 30,2 & 30,2 & - & 4,2 & 6,8 & 16,9 & 6,2 & 7,4 & 0,55 & 9,4 & 0,14 & 9,2 \\
\hline 1958 & 31,8 & 31,0 & 0,8 & 5,5 & 6,8 & 16,6 & 6,3 & 7,5 & 0,56 & 9,0 & 0,14 & 9,8 \\
\hline 1959 & 34,6 & 34,6 & - & 5,4 & 7,2 & 19,0 & 6,6 & 7,9 & 0,59 & 11,0 & 0,10 & 10,2 \\
\hline 1960 & 36,3 & 35,3 & 1,0 & 5,9 & 7,3 & 19,5 & 6,7 & 8,2 & 0,60 & 11,1 & 0,09 & 10,9 \\
\hline 1961 & 36,9 & 34,0 & 2,9 & 6,5 & 7,1 & 20,4 & 6,4 & 8,2 & 0,61 & 12,2 & 0,07 & 10,0 \\
\hline
\end{tabular}

Fuentes: *Impuesto de Contribución Industrial y del Comercio (1917 y 1927), Sindicato Vertical (O Nacional) de Agua, Gas y Electricidad. Servicio Sindical de Estadística (1944-1964).

Notas: D: electricidad distribuida, P: electricidad producida, Ad: electricidad adquirida, Abon: abonados, Pérd: pérdidas, FFCC: Ferrocarril eléctrico. 